\title{
P2X7 receptors on osteoblasts couple to production of lysophosphatidic acid: a signaling axis promoting osteogenesis
}

\author{
Nattapon Panupinthu, ${ }^{1,2}$ Joseph T. Rogers, ${ }^{1}$ Lin Zhao, ${ }^{3}$ Luis Pastor Solano-Flores, ${ }^{1,2}$ Fred Possmayer, ${ }^{3,4}$ \\ Stephen M. Sims, ${ }^{1,2}$ and S. Jeffrey Dixon ${ }^{1,2}$ \\ 'Canadian Institutes of Health Research Group in Skeletal Development and Remodeling, ${ }^{2}$ Department of Physiology and Pharmacology, ${ }^{3}$ Department of Obstetrics \\ and Gynaecology, and ${ }^{4}$ Department of Biochemistry, The University of Western Ontario, London, ON, Canada N6A 5Cl
}

$\mathrm{N}$ ucleotides are released from cells in response to mechanical stimuli and signal in an autocrine/ paracrine manner through cell surface P2 receptors. $P 2 r \times 7^{-1-}$ mice exhibit diminished appositional growth of long bones and impaired responses to mechanical loading. We find that calvarial sutures are wider in $P 2 r x 7^{-1-}$ mice. Functional P2X7 receptors are expressed on osteoblasts in situ and in vitro. Activation of P2X7 receptors by exogenous nucleotides stimulates expression of osteoblast markers and enhances mineralization in cultures of rat calvarial cells. Moreover, osteogenesis is sup-

\section{Introduction}

The skeletal system develops and adapts throughout life in response to hormones, cytokines, and external factors such as mechanical loading. Maintenance of bone mass in adults is a dynamic process that involves a balance of resorption by osteoclasts and formation by osteoblasts. For $>100 \mathrm{yr}$, it has been known that bone is remodeled in accordance with the stresses placed upon it (Frost, 2001). Unloading of the skeleton decreases osteogenesis, and mechanotransduction is now recognized as one of the major factors regulating skeletal mass (Robling et al., 2006).

Nucleotides, such as ATP, are thought to be key mediators in the response of bone cells to mechanical stimuli (Dixon and Sims, 2000; Robling et al., 2006). Many cells release ATP when subjected to stretch or fluid shear (Romanello et al., 2001; Genetos et al., 2005; Riddle et al., 2007). Extracellular ATP can then signal through P2 nucleotide receptors present on various cell types including osteoblasts. There are two subtypes of P2

Correspondence to S. Jeffrey Dixon: jeff.dixon@schulich.uwo.ca

Abbreviations used in this paper: ALP, alkaline phosphatase; BEL, bromoenol lactone; BzATP, 2', 3'-O-(4-benzoylbenzoyl)-ATP; COX, cyclooxygenase; LPA, lysophosphatidic acid; $\mathrm{PGE}_{2}$, prostaglandin $\mathrm{E}_{2} ; \mathrm{PLA}_{2}$, phospholipase $\mathrm{A}_{2} ; \operatorname{PPAR} \gamma$, peroxisome proliferator-activated receptor $\gamma$.

The online version of this paper contains supplemental material. pressed in calvarial cell cultures from $P 2 r x 7^{-1-}$ mice compared with the wild type. P2X7 receptors couple to production of the potent lipid mediators lysophosphatidic acid (LPA) and prostaglandin $E_{2}$. Either an LPA receptor antagonist or cyclooxygenase (COX) inhibitors abolish the stimulatory effects of P2X7 receptor activation on osteogenesis. We conclude that P2X7 receptors enhance osteoblast function through a cell-autonomous mechanism. Furthermore, a novel signaling axis links P2X7 receptors to production of LPA and COX metabolites, which in turn stimulate osteogenesis. receptors, P2X (ligand-gated cation channels) and P2Y (G proteincoupled receptors; Burnstock, 2007). Osteoblasts express multiple subtypes of P2X and P2Y receptors (Dixon and Sims, 2000; Hoebertz et al., 2000), but the mechanistic basis of nucleotide effects on bone is not clear.

P2X7 receptors function not only as nonselective cation channels but can also induce the formation of large membrane pores, which allow passage of molecules with size up to $900 \mathrm{kD}$ (North, 2002; Khakh and North, 2006). Pore formation may arise from dilation of the channel caused by recruitment of additional subunits. However, recent evidence supports the possibility that $\mathrm{P} 2 \mathrm{X} 7$ receptor activation leads to opening of a distinct pore protein in the plasma membrane (Pelegrin and Surprenant, 2006).

P2X7 receptors have been implicated in skeletal remodeling and mechanotransduction. $P 2 r x 7^{-1-}$ mice exhibit decreased periosteal bone formation in long bones without a difference in length (Ke et al., 2003). Moreover, $P 2 r x 7^{-/-}$mice show reduced osteogenesis in response to mechanical loading (Li et al., 2005). We have recently shown that activation of P2X7 receptors induces dynamic membrane blebbing in a subpopulation of calvarial cells (Panupinthu et al., 2007). Despite these findings that link $\mathrm{P} 2 \mathrm{X} 7$ receptors to anabolic effects on 


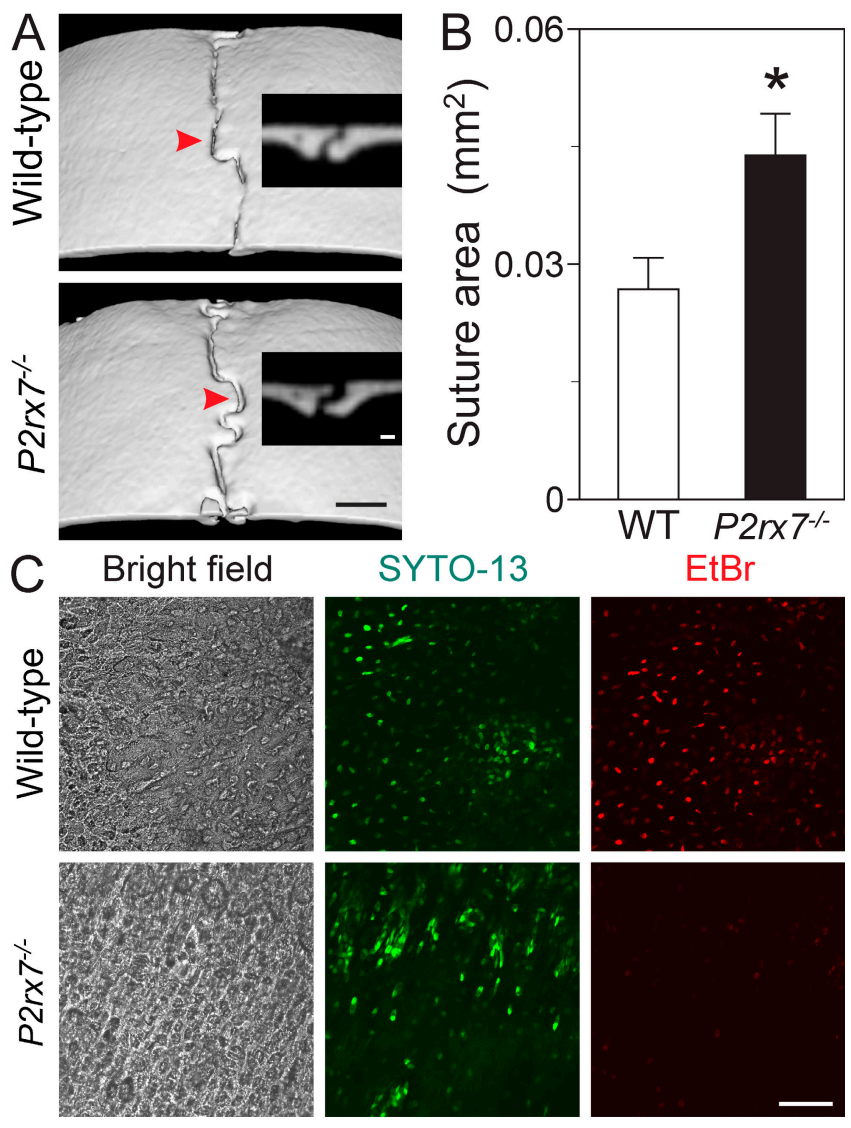

Figure 1. Characterization of calvariae from $\mathbf{P} 2 \mathrm{rx} \mathbf{7}^{-/-}$mice. (A) Reconstructed images obtained using microcomputed tomography show ectocranial surface of the parietal bones from 9-mo-old male wild-type and $P 2 r x 7^{-1-}$ mice. Bar, $1 \mathrm{~mm}$. Insets show sagittal sutures viewed in the coronal planes indicated by red arrowheads. Bar, $100 \mu \mathrm{m}$. Calvariae from $P 2 r x 7^{-1-}$ mice display wider sutures compared with the wild type. (B) Mean area of sagittal sutures was calculated from 10 coronal sections along the suture length. Larger suture area was observed in $\mathrm{P} 2 \mathrm{r} \times 7^{-1-}$ mice compared with the wild type (WT; ${ }^{*}, \mathrm{P}<0.05 ; n=10-12$ mice). Data are means \pm SEM. (C) Calvariae were dissected from wild-type and $P 2 r \times 7^{-1-}$ newborn mice and parietal bones were incubated in nominally divalent cation-free buffer for $10 \mathrm{~min}$ at $37^{\circ} \mathrm{C}$. Paired samples were then exposed to $300 \mu \mathrm{M}$ BzATP (depicted) or vehicle (not depicted) for $10 \mathrm{~min}$. Fluorescent dyes, $5 \mu \mathrm{M}$ SYTO-13 (cell-permeable nucleic acid stain), and $20 \mathrm{\mu g} / \mathrm{ml}$ ethidium bromide (EłBr; normally impermeant DNA stain) were added for an additional $2 \mathrm{~min}$ in the presence of BzATP or vehicle. Bright field images show ectocranial surfaces of calvariae (left). Confocal images of the same fields show all cells labeled with SYTO-13 (middle, green). BzATP induced uptake of ethidium bromide (indicating pore formation) by cells on the surface of calvariae from wild-type but not $P 2 r \times 7^{-/-}$mice (right, red). Ethidium bromide uptake in vehicle-treated calvariae from wildtype and $P 2 r x 7^{-1-}$ mice was virtually undetectable (not depicted). Data are representative of four fields each from six to eight mice from three different litters. Bar, $100 \mu \mathrm{m}$.

the skeleton, it is not known how these receptors influence osteogenesis. Moreover, it is not known whether the phenotype of the $P 2 r x 7^{-/-}$mouse is caused by an intrinsic defect in osteoblasts or by an indirect effect mediated by other cell types. In this regard, the $\mathrm{P} 2 \mathrm{X} 7$ receptor is expressed in cells of the monocyte/macrophage lineage, including osteoclasts (Naemsch et al., 2001), as well as some endocrine cell types.

In the present study, we discovered a cell-autonomous role for $\mathrm{P} 2 \mathrm{X} 7$ receptors in bone formation. We show that activation of $\mathrm{P} 2 \mathrm{X} 7$ receptors leads to production of lysophosphatidic acid (LPA) as well as cyclooxygenase (COX) metabolites. These lipid mediators then up-regulate expression of osteoblast marker genes and stimulate mineralization. Thus, we establish the existence of a P2X7-LPA signaling axis that regulates osteoblast differentiation and osteogenesis during skeletal remodeling and mechanotransduction.

\section{Results}

\section{Characteristics of calvariae from Perx $7^{-1-}$ mice}

Mice lacking P2rx7 exhibit decreased periosteal bone formation in the tibia and insensitivity of the ulna to mechanical loading (Ke et al., 2003; Li et al., 2005). To further explore the role of this receptor in osteogenesis, we examined the calvariae of wild-type and $P 2 r x 7^{-/-}$mice using microcomputed tomography. Unlike long bones, which form primarily through endochondral ossification, calvariae form through intramembranous ossification and are not subject to weight bearing. Surprisingly, we found that calvarial sutures were wider in $P 2 r x 7^{-/-}$mice compared with age- and sex-matched wild-type controls (Fig. 1 A). There was no significant difference in calvarial thickness in the region of the suture. Quantitative analysis revealed that the cross sectional suture area between parietal bones was $\sim 40 \%$ greater in $P 2 r x 7^{-/}$mice compared with the wild type (Fig. $1 \mathrm{~B}$ ). Thus, $P 2 r x 7^{-1-}$ mice exhibit calvarial defects, which are evident at sutures which experience tensile strain caused by intracranial pressure (Henderson et al., 2005).

To investigate whether calvarial cells in situ express functional $\mathrm{P} 2 \mathrm{X} 7$ receptors, we assessed $\mathrm{P} 2 \mathrm{X} 7$-induced pore formation (Fig. 1 C). Calvariae were removed from newborn wild-type and $P 2 r x 7^{-1-}$ mice. Parietal bones were incubated in $300 \mu \mathrm{M}$ 2',3'-O-(4-benzoylbenzoyl)-ATP (BzATP; a relatively potent P2X7 agonist) or vehicle. Cells were stained with SYTO-13 (green), a permeant dye that labels all cells, and ethidium bromide (red), a normally impermeant dye that is taken up only when pores are present. The ectocranial surface of parietal bones was observed using bright field (Fig. $1 \mathrm{C}$, left) and confocal microscopy. All cells were stained with SYTO-13 (Fig. 1 C, middle, green). BzATP induced uptake of ethidium bromide in calvariae from wild-type but not $P 2 r x 7^{-/-}$mice (Fig. $1 \mathrm{C}$, right, red). In contrast, when calvariae from wild-type and $P 2 r x 7^{-/-}$ mice were not exposed to BzATP, ethidium bromide uptake was virtually undetectable ( $n=6-8$ calvariae; unpublished data). Thus, we show for the first time that functional $\mathrm{P} 2 \mathrm{X} 7$ receptors are present on bone cells in situ.

\section{Functional PEX7 receptors are expressed in osteoblasts in vitro}

Previous in vitro studies have revealed that a subpopulation of rodent calvarial cells expresses P2X7 receptors (Ke et al., 2003; Panupinthu et al., 2007). In this paper, we found that a subpopulation of marrow stromal cells isolated from rat long bones also expresses functional $\mathrm{P} 2 \mathrm{X} 7$ receptors (Fig. S1, available at http:// www.jcb.org/cgi/content/full/jcb.200708037/DC1). However, the identity of these subpopulations is not known. Moreover, it has not been established whether the effects of $\mathrm{P} 2 \mathrm{X} 7$ receptors 

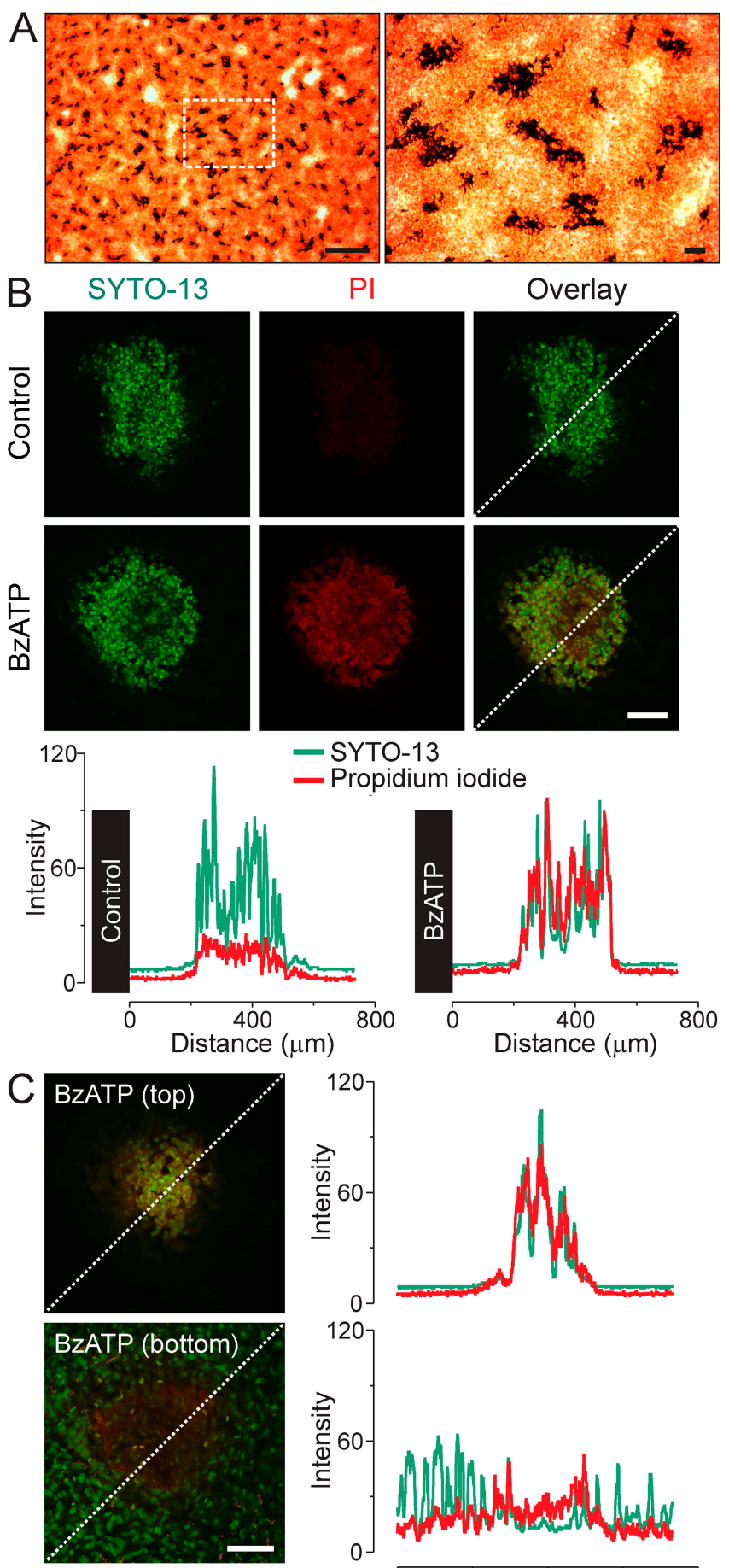

0

0

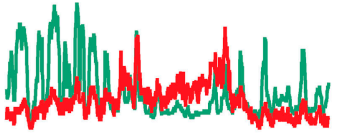

Distance $(\mu \mathrm{m})$

Figure 2. Cells in bone nodules express $\mathbf{P} 2 X 7$ receptors. Cultures of rat calvarial cells were supplemented with $50 \mathrm{\mu g} / \mathrm{ml}$ ascorbic acid and $2 \mathrm{mM}$ $\beta$-glycerophosphate at day 0 . (A) Selected cultures were fixed and stained for ALP activity (red) and mineral deposition (black). Representative image of a day-21 culture is shown at left. Higher magnification image of region indicated by dashed box shows individual nodules (right). Bars: (left) $1 \mathrm{~mm}$; (right) $100 \mu \mathrm{m}$. (B) In other experiments, pore formation was assessed in live calvarial cell cultures (days 14-21). Cells were exposed to $300 \mu \mathrm{M}$ BzATP or vehicle (control). Pore formation was detected using confocal microscopy in a plane through the midregion of the nodule $(\sim 25 \mu \mathrm{m}$ above substrate). All cells were stained with SYTO-13 (left, green). BzATP induced uptake of propidium iodide (middle, red) by cells within nodules. Below the images are linear intensity profiles, obtained where indicated by dashed lines, illustrating colocalization of probes in cultures exposed on bone formation in vivo are osteoblast autonomous. To investigate these questions, we used a well-characterized bone formation assay using calvarial cells isolated from newborn rodents. In rat calvarial cell cultures, supplementation of the medium with $50 \mu \mathrm{g} / \mathrm{ml}$ ascorbic acid and $2 \mathrm{mM} \beta$-glycerophosphate induced osteoblast differentiation and bone nodule formation (Fig. 2 A). Alkaline phosphatase (ALP) activity was detected using cytochemical staining (red). Mineral deposition was revealed by staining with silver nitrate solution (von Kossa; black). After $14 \mathrm{~d}$ of supplementation, mineralized areas were centrally located within regions displaying ALP activity, indicating the presence of active osteoblasts.

We first determined expression of functional P2X7 receptors in differentiated rat calvarial cell cultures using the pore formation assay. Uptake of propidium iodide was monitored after treatment with $300 \mu \mathrm{M}$ BzATP or vehicle (control). We examined confocal images in an xy plane near the midregion of nodules ( $\sim 25 \mu \mathrm{m}$ above the substrate). Nuclei were visualized with SYTO-13 (Fig. 2 B, left). BzATP induced uptake of propidium iodide (Fig. 2 B, middle), and colocalization of SYTO-13 and propidium iodide was observed (Fig. $2 \mathrm{~B}$, right). Intensity profiles along the dotted lines revealed colocalization of SYTO-13 and propidium iodide in cultures treated with BzATP but not in control. These data establish the presence of functional P2X7 receptors in bone nodule cells. When images were examined in an xy plane at the top of the nodule (in this case, $30 \mu \mathrm{m}$ above the substrate), robust pore formation was observed in response to BzATP (Fig. 2 C, top). In contrast, cells located in the monolayer between nodules ( $6 \mu \mathrm{m}$ above the substrate) did not exhibit pore formation, indicating that these less differentiated cells do not express functional $\mathrm{P} 2 \mathrm{X} 7$ receptors (Fig. $2 \mathrm{C}$, bottom).

We next evaluated $\mathrm{P} 2 \mathrm{X} 7$ receptor expression during the differentiation of rat and murine calvarial cells. When medium was supplemented with ascorbic acid and $\beta$-glycerophosphate, expression of $P 2 r x 7$ in cultures from wild-type mice was found to increase $2.9 \pm 0.3$-fold over $14 \mathrm{~d}$ (assessed using quantitative real-time RT-PCR; $n=3$ independent experiments analyzed by paired $t$ test; $\mathrm{P}<0.05)$. Expression of $P 2 r x 7$ also increased during the differentiation of rat calvarial cells (levels assessed at days 0 and $7 ; n=3$ independent experiments; $\mathrm{P}<0.05)$. Collectively, these data demonstrate that the calvarial cells responsible for osteogenesis in vivo and in vitro express functional $\mathrm{P} 2 \mathrm{X} 7$ receptors.

\section{BzATP enhances osteogenesis in rat calvarial cell cultures}

Having established that osteoblasts in calvarial cell cultures express functional $\mathrm{P} 2 \mathrm{X} 7$ receptors, we next investigated the effects of receptor activation on osteogenesis. To monitor the

to BzATP. (C) The same BzATP-treated nodule shown in B was scanned in multiple focal planes parallel to the substrate. Overlay images and intensity profiles are from focal planes near the top (in this case, $30 \mu \mathrm{m}$ above the substrate) and bottom (6 $\mu \mathrm{m}$ above the substrate) of the nodule. BzATP induced pore formation in cells specifically located in the nodule but not in the monolayer between nodules. Data in $B$ and $C$ are representative of four independent preparations. Bars, $100 \mu \mathrm{m}$. 

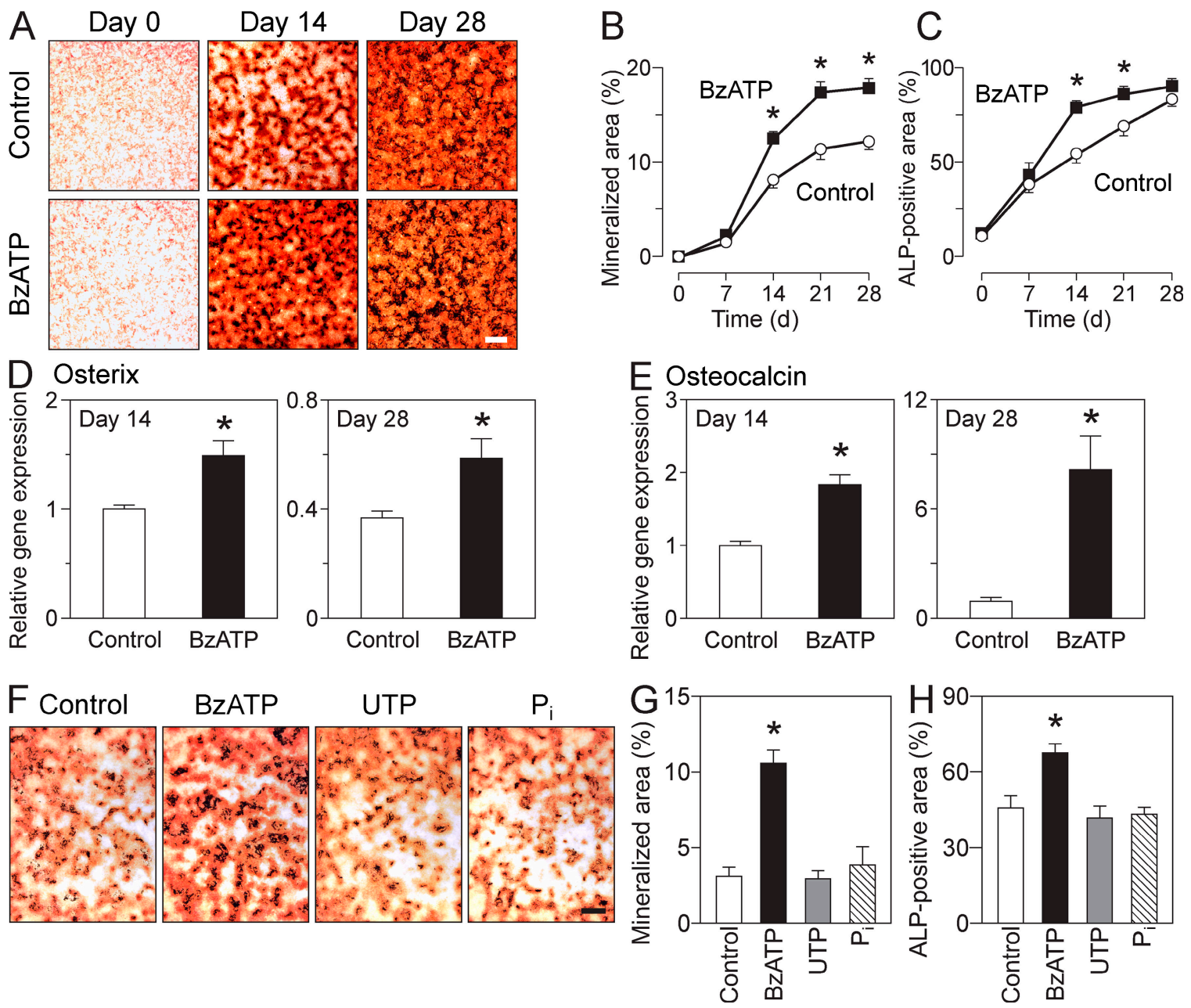

Figure 3. BzATP enhances osteogenesis. (A) Rat calvarial cells were differentiated in medium containing physiological concentrations of $\mathrm{Ca}^{2+}$ and $\mathrm{Mg}^{2+}$. Cultures were treated with $100 \mu \mathrm{M}$ BzATP or vehicle (control) beginning at day 0 for up to $28 \mathrm{~d}$. BzATP enhanced ALP activity and mineral deposition in rat calvarial cell cultures. Bar, $1 \mathrm{~mm}$. (B and C) Mineralized area $(B)$ and ALP-positive area $(C)$ were quantified using 2D image analysis. Areas are expressed as a percentage of total area. BzATP promoted mineralization and accelerated the appearance of ALP activity. Data are means \pm SEM $(n=4$ independent preparations). ${ }^{*}$, significant difference compared with control $(P<0.05)$. (D and $\left.E\right)$ Next, total RNA was isolated from differentiated rat calvarial cell cultures at the times indicated. Expression levels of genes encoding osterix (D) and osteocalcin (E) were analyzed using real-time RT-PCR. Data are expressed relative to values in control cultures at day 14. BzATP increased expression of both genes. Data are means \pm SEM $(n=3$ independent preparations). *, significant effect of BzATP compared with control at the corresponding time $(\mathrm{P}<0.05)$. (F) Cultures were treated with vehicle (control), $100 \mu M$ BzATP, $100 \mu M$ UTP (P2Y-selective agonist), or an equivalent concentration of $P_{i}(300 \mu M)$ beginning at day 0 for $14 \mathrm{~d}$. Bar, $1 \mathrm{~mm}$. (G and H) BzATP, but not UTP or $P_{i}$, promoted mineralization $(G)$ and ALP activity $(H)$. Data are means \pm SEM ( $n=4$ independent preparations). ${ }^{*}$, significant difference compared with control $(\mathrm{P}<0.05)$.

formation of bone nodules, mineralized and ALP-positive areas were assessed at 7-d intervals. As expected, both parameters increased in the presence of ascorbic acid and $\beta$-glycerophosphate over $28 \mathrm{~d}$ in control cultures. $100 \mu \mathrm{M}$ BzATP stimulated mineralization and ALP activity (Fig. 3 A). Analysis of mineralized area indicated that BzATP significantly enhanced the extent of mineralization compared with the control from 14-28 d, with a $40 \%$ increase at day 28 (Fig. 3 B). In addition, BzATP accelerated the development of ALP activity, with significant increases at 14 and $21 \mathrm{~d}$ but reaching the same level by $28 \mathrm{~d}$ (Fig. $3 \mathrm{C}$ ). Data from all bone formation assays were pooled from at least three independent experiments.

We next assessed expression of osteoblast marker genes in rat calvarial cell cultures using real-time RT-PCR. Consistent with its effects on nodule formation, $100 \mu \mathrm{M}$ BzATP significantly up-regulated levels of transcripts encoding osterix and osteocalcin at 14 and $28 \mathrm{~d}$ (Fig. 3, D and E). Expression of the gene encoding osteocalcin (marker of late-stage osteoblast differentiation) was dramatically enhanced by BzATP at $28 \mathrm{~d}$. Thus, BzATP acts on cells of the osteoblast lineage to upregulate the genes encoding osterix and osteocalcin and to promote osteogenesis.

It is known that BzATP activates several P2 nucleotide receptors in addition to P2X7 (North, 2002). Thus, we investigated which $\mathrm{P} 2$ receptor subtypes mediate the stimulatory effects of BzATP on bone formation using UTP, an agonist for several P2Y receptors but ineffective at all P2X receptors (Burnstock, 2007). Moreover, ALP present on the surface of osteoblasts can hydrolyze nucleotides, causing release of $P_{i}$ that promotes mineralization at sufficiently high concentrations. Although $100 \mu \mathrm{M}$ BzATP increased mineral deposition and ALP activity, $100 \mu \mathrm{M}$ UTP did not (Fig. 3, F-H). Similarly, an equivalent concentration of $\mathrm{P}_{\mathrm{i}}$ 

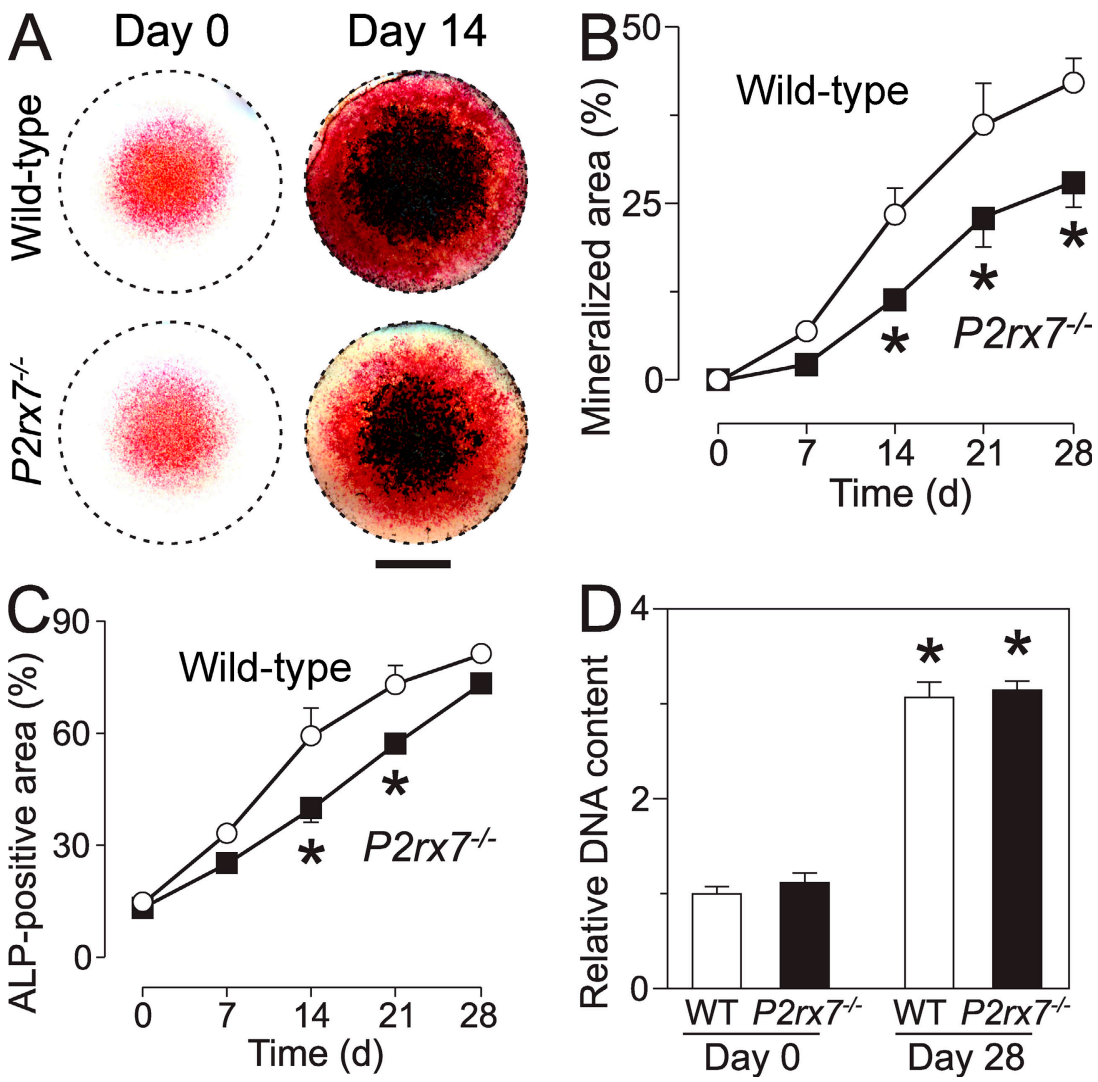

Figure 4. Reduced osteogenesis in cultures of calvarial cells from $\mathrm{P} 2 \mathrm{rx} \mathbf{7}^{-1-}$ mice. (A) Calvarial cells from wild-type and $P 2 r x 7^{-1-}$ mice were cultured in medium containing physiological concentrations of $\mathrm{Ca}^{2+}$ and $\mathrm{Mg}^{2+}$. At day $\mathrm{O}$, culture medium was supplemented with ascorbic acid and $\beta$-glycerophosphate without exogenous nucleotides. Images show representative micromass cultures (equivalent fields). Bar, $0.5 \mathrm{~cm}$. (B and C) Calvarial cell cultures from $P 2 r \times 7^{-/-}$ mice showed decreased mineral deposition (B) and delayed development of ALP activity (C) compared with wild-type cultures. Data are means \pm SEM $(n=3$ independent preparations). ${ }^{*}$, significant difference compared with wild type $(P<0.05)$. (D) DNA content of selected cultures was assessed using HOECHST 33342. Data are expressed relative to DNA content in wild-type cultures at day 0 . As expected, DNA content increased from day 0 to 28 , however there was no significant difference between cultures from wild-type and $P 2 r \times 7^{-1-}$ mice. Data are means \pm SEM ( $n=3-4$ independent preparations). * , significant difference compared with day $0(P<0.05)$
$(300 \mu \mathrm{M})$ had no effect. Thus, activation of P2Y receptors is not sufficient to stimulate osteogenesis, and the modest increase in $\mathrm{P}_{\mathrm{i}}$ levels from nucleotide hydrolysis cannot account for the enhancement of mineralization observed.

To evaluate the role of endogenous nucleotides, rat calvarial cell cultures were differentiated in the absence of exogenous nucleotides with and without apyrase, a diphosphohydrolase that breaks down extracellular nucleotides. 10 units/ml apyrase decreased ALP activity (at $14 \mathrm{~d}$, ALP-positive area was $50 \pm 3 \%$ in control cultures vs. $39 \pm 2 \%$ in cultures treated with apyrase; $n=3$ independent experiments; $\mathrm{P}<0.05)$. This finding is consistent with constitutive release of endogenous nucleotides from calvarial cells, which has been reported previously in an osteoblast-like cell line (Buckley et al., 2003).

\section{Diminished mineralization and ALP activity in cultures from $P 2 r \times 7^{-/-}$mice}

To further investigate the role of $\mathrm{P} 2 \mathrm{X} 7$ receptors in osteogenesis, we compared nodule formation in cultures of calvarial cells from wild-type and $P 2 r x 7^{-/-}$mice. Medium was supplemented with ascorbic acid and $\beta$-glycerophosphate without exogenous nucleotides (in contrast to the experiments shown in Fig. 3, where BzATP was added). Cultures from $P 2 r x 7^{-1-}$ mice showed a marked decrease in mineralization compared with wild-type murine cultures, with a $33 \%$ reduction at day 28 (Fig. 4, A and B). Moreover, the development of ALP activity was delayed in cultures from $P 2 r x 7^{-/-}$mice, with significantly less activity at 14 and $21 \mathrm{~d}$ (Fig. 4, A and C). Thus, osteogenesis is diminished in cultures from $P 2 r x 7^{-1-}$ mice, supporting a role for $\mathrm{P} 2 \mathrm{X} 7$ receptors in stimulating bone formation. Moreover, the fact that this difference was observed in the absence of exogenous nucleotides provides further evidence for constitutive nucleotide release.

We next investigated whether the difference in osteogenesis in cultures from wild-type and $P 2 r x 7^{-1-}$ mice could arise from changes in the proliferation or survival of calvarial cells. However, DNA analysis revealed no significant difference in cell numbers between $P 2 r x 7^{-/-}$and wild-type cultures at 0 and $28 \mathrm{~d}$ (Fig. 4 D). These data and those presented in Fig. 3 indicate that $\mathrm{P} 2 \mathrm{X} 7$ receptors stimulate bone formation, possibly by enhancing osteoblast differentiation.

Gene expression in cultures of calvarial cells from wild-type and $P 2 r \times 7^{-1-}$ mice

To explore the role of $P 2 r x 7$ in osteoblast differentiation, we assessed expression levels of marker genes in cultures from wild-type and $P 2 r x 7^{-1-}$ mice at 7-d intervals up to $28 \mathrm{~d}$, without exogenous nucleotides. There was no significant difference in levels of Runx2 transcripts in wild-type and $P 2 r x 7^{-/-}$ cultures (Fig. 5). Osterix transcript levels were dramatically suppressed in $P 2 r x 7^{-/-}$cultures at day 7 , a time that corresponded to the initiation of nodule formation. Expression of the gene encoding bone sialoprotein was diminished fivefold in $P 2 r x 7^{-1-}$ cultures at $7 \mathrm{~d}$, closely reflecting the changes in osterix expression. Furthermore, transcript levels of osteocalcin were markedly suppressed from $7-21 \mathrm{~d}$ in $P 2 r x 7^{-1-}$ cultures (2-13-fold).

Because there is lineage allocation during differentiation of mesenchymal cells, we next investigated the expression of adipocyte and chondrocyte markers. At day 7, transcript levels of the adipocyte marker peroxisome proliferator-activated 

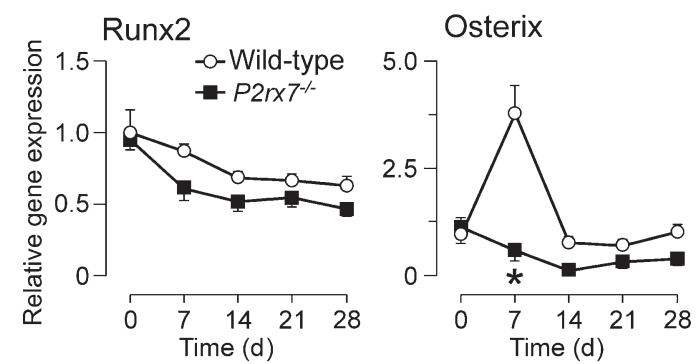

Bone sialoprotein

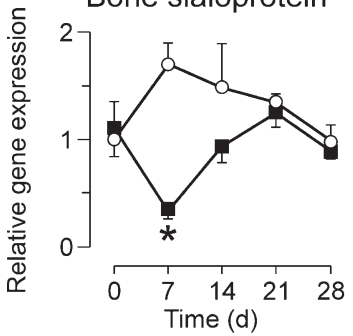

Osteocalcin

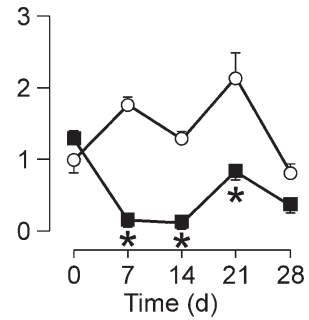

Lipoprotein lipase
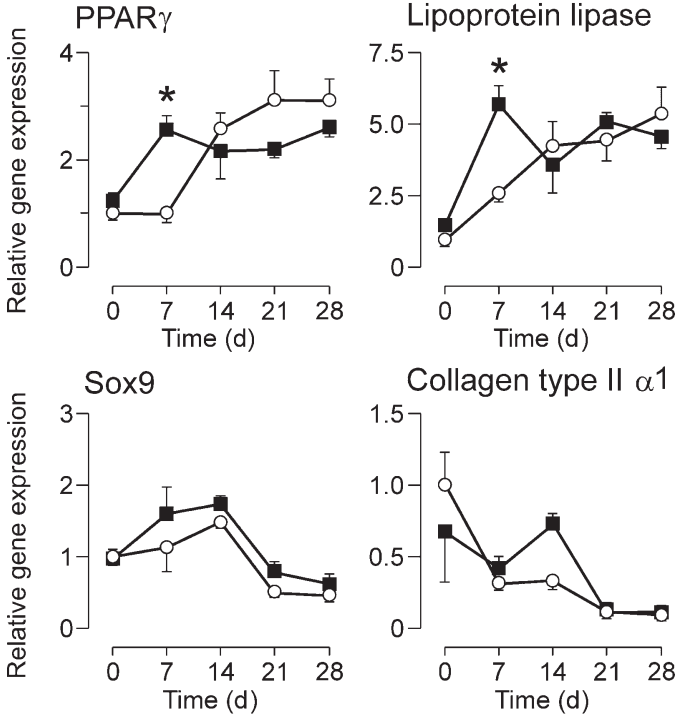

Collagen type II $\alpha 1$

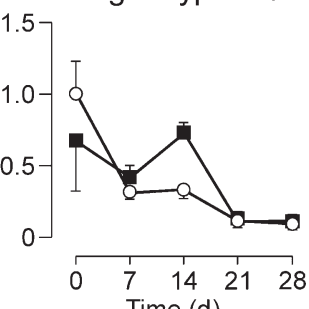

Figure 5. Gene expression in cultures of calvarial cells from wild-type and $P 2 r x 7^{-1-}$ mice. Cultures of calvarial cells from wild-type and $P 2 r x 7^{-1-}$ mice were supplemented at day 0 with ascorbic acid and $\beta$-glycerophosphate without exogenous nucleotides. Total RNA was isolated at the times indicated. Real-time RT-PCR was used to analyze expression levels of genes encoding osteoblast markers (Runx2, osterix, bone sialoprotein, and osteocalcin), adipocyte markers (PPAR $\gamma$ and lipoprotein lipase), and chondrocyte markers (Sox9 and collagen type II $\alpha 1$ ). Data are expressed relative to values in wild-type cultures at day 0 . Cultures from $P 2 r \times 7^{-1-}$ mice showed significant decreases in expression levels of osteoblast marker genes, except Runx2. Cultures from $P 2 r x 7^{-1-}$ mice also showed increased levels of adipocyte markers at day 7 . However, there were no differences in levels of chondrocyte markers. Data are means \pm SEM $(n=3$ independent preparations). ${ }^{*}$, significant difference compared with wild type at the corresponding time $(\mathrm{P}<0.05)$.

receptor $\gamma(\operatorname{PPAR} \gamma)$ were significantly increased (approximately threefold) in cultures from $P 2 r x 7^{-/-}$compared with wild-type mice (Fig. 5). Similarly, expression of the gene encoding lipoprotein lipase, which is regulated by $\operatorname{PPAR} \gamma$, was increased in $P 2 r x 7^{-/-}$cultures at day 7 . In contrast, the absence of $\mathrm{P} 2 \mathrm{X} 7$ receptors did not significantly affect levels of the chondrocyte marker genes encoding Sox 9 and collagen type II $\alpha 1$. These data indicate simultaneous up-regulation of adipocyte differentiation and down-regulation of osteoblast
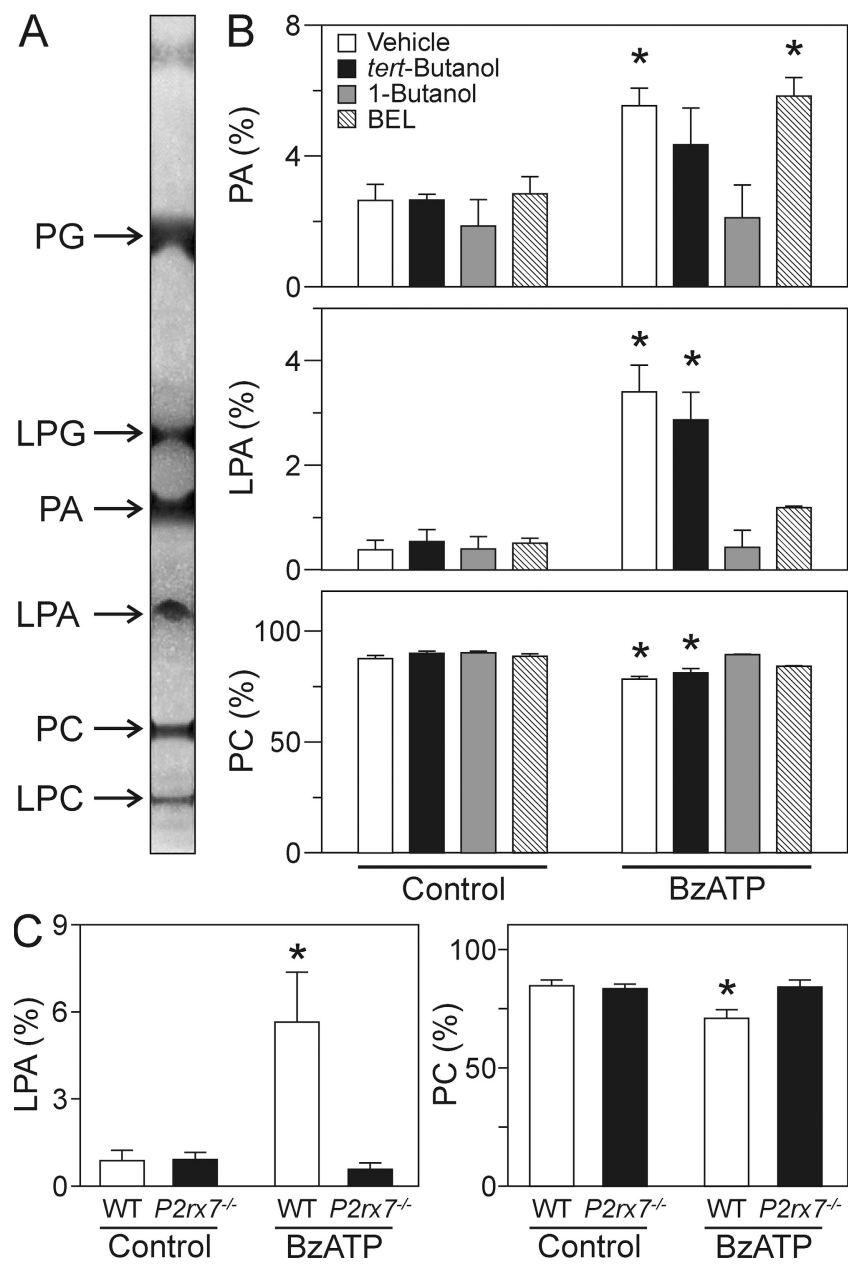

Figure 6. $\mathbf{P} 2 X 7$ receptors activate PLD and $\mathrm{PLA}_{2}$ leading to production of LPA. (A) Representative thin layer chromatograph illustrating the following reference lipids: PG, phosphatidylglycerol; LPG, lysophosphatidylglycerol; PA, phosphatidic acid; LPA; PC, phosphatidylcholine; and LPC, lysophosphatidylcholine (phosphatidylethanolamine was omitted for clarity). (B) Rat calvarial cells were labeled with $1 \mu \mathrm{Ci} / \mathrm{ml}\left[{ }^{14} \mathrm{C}\right]$ glycerol at $37^{\circ} \mathrm{C}$ for $18 \mathrm{~h}$. Cells were then incubated for $10 \mathrm{~min}$ at $37^{\circ} \mathrm{C}$ with $1 \% \mathrm{vol} / \mathrm{vol} 1$-butanol (PLD inhibitor), $1 \% \mathrm{vol} / \mathrm{vol}$ tert-butanol (inactive analogue of 1-butanol), $10 \mu \mathrm{M}$ BEL (PLA $A_{2}$ inhibitor), or vehicle. $300 \mu \mathrm{M}$ BzATP or its vehicle (control) was then added and cultures were incubated for an additional $20 \mathrm{~min}$ in the continued presence of inhibitors. Lipids were extracted from the cell layer and separated by thin layer chromatography. The percentages of radioactivity in $\left[{ }^{14} \mathrm{C}\right]$ phosphatidic acid, $\left[{ }^{14} \mathrm{C}\right] \mathrm{LPA}$, and $\left[{ }^{14} \mathrm{C}\right]$ phosphatidylcholine were determined. (C) Calvarial cells isolated from wild-type (WT) and $P 2 r x 7^{-1-}$ mice were labeled with $\left[{ }^{14} \mathrm{C}\right]$ glycerol. $300 \mu \mathrm{M} \mathrm{BzATP}$ or its vehicle (control) was added and cultures were incubated for $20 \mathrm{~min}$. Lipids were extracted from the cell layer and separated by thin layer chromatography. The percentages of radioactivity in $\left[{ }^{14} \mathrm{C}\right] \mathrm{LPA}$ and $\left[{ }^{14} \mathrm{C}\right]$ phosphatidylcholine were determined. Data are means \pm SEM ( $n=3$ independent preparations). ${ }^{*}$, significant difference compared with the corresponding control $(P<0.05)$.

differentiation in $P 2 r x 7^{-/-}$cell cultures. Collectively, our findings from the rat and murine systems (Figs. 2-5) establish that $\mathrm{P} 2 \mathrm{X} 7$ receptors promote osteogenesis through a cell-autonomous mechanism by directing cells toward the osteoblast lineage.

\section{$P 2 \times 7$ receptors couple to production of} LPA through activation of phospholipases In our previous study, lipid signaling was implicated in the pathway underlying P2X7-induced membrane blebbing of calvarial cells (Panupinthu et al., 2007). Therefore, we used a biochemical 

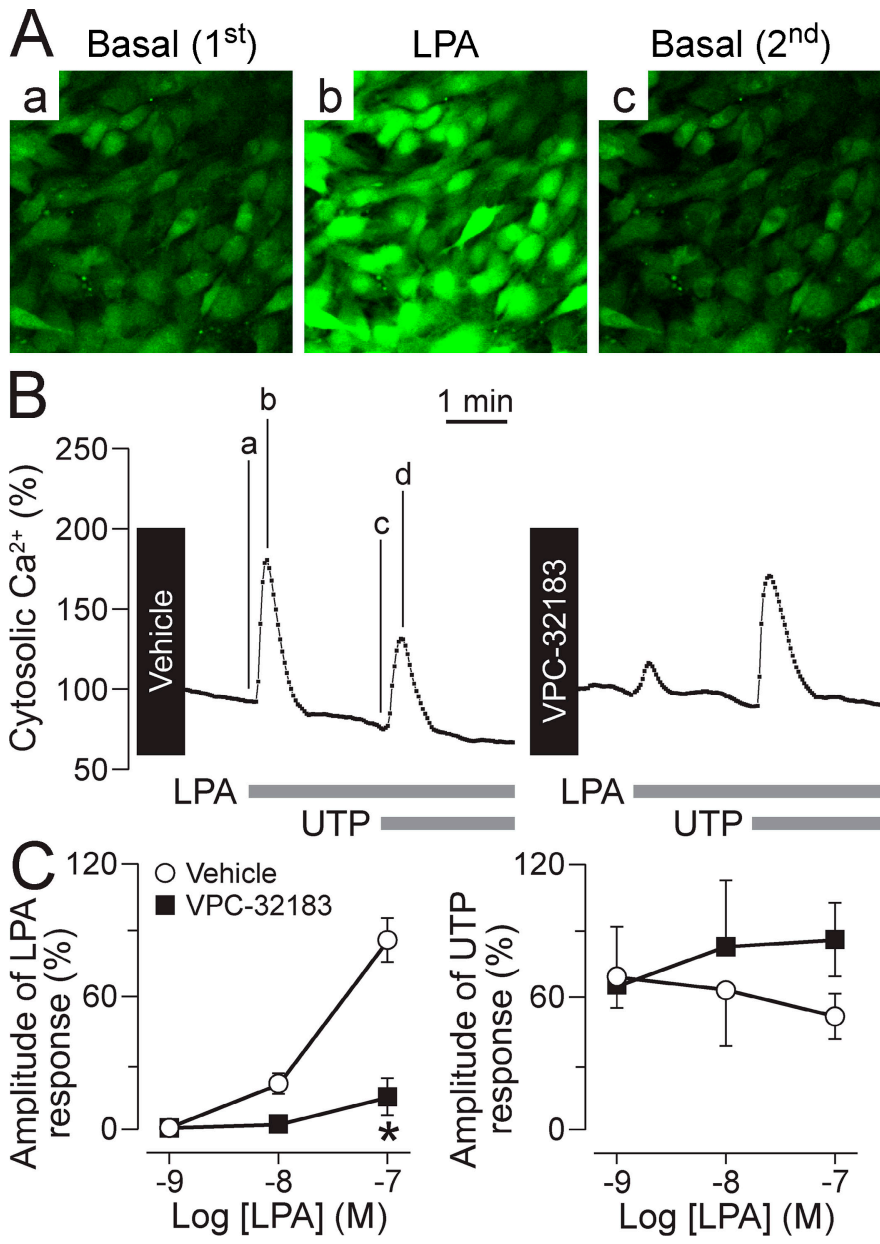

$1 \mathrm{~min}$
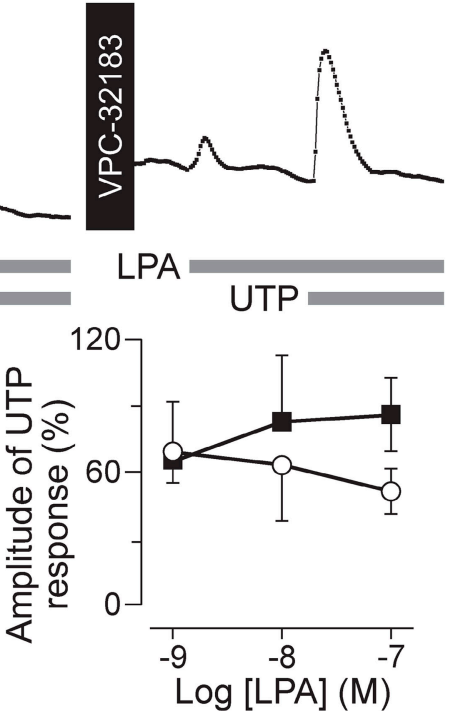

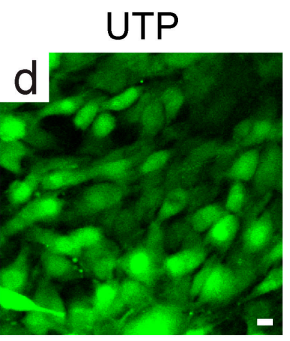

Figure 7. The LPA receptor antagonist VPC32183 inhibits LPA-induced elevation of $\left[\mathrm{Ca}^{2+}\right]_{\text {i }}$. Rat calvarial cells were isolated and cultured for 7-9 d on 35-mm glass bottom dishes, without ascorbic acid or $\beta$-glycerophosphate. Cells were loaded with the $\mathrm{Ca}^{2+}$-sensitive probe fluo-4 and fluorescence intensity was measured using confocal microscopy. Cells were bathed in serum-free medium at room temperature for 20 min with vehicle or 1 MM VPC-32183 (LPA l/3 receptor antagonist) and then challenged sequentially with $100 \mathrm{nM}$ LPA and 100 pM UTP (which activates calcium mobilizing P2Y receptors on osteoblasts). (A) Micrographs of a representative field in a vehicle-treated culture show basal fluorescence (a), peak of the response to LPA (b), before adding UTP (c), and peak response to UTP (d). Both LPA and UTP caused transient increase in the fluorescence intensity of fluo-4. Bar, $10 \mu \mathrm{m}$. (B) Graphs show time course of $\left[\mathrm{Ca}^{2+}\right]_{i}$ changes in the whole field. Data are expressed as percentages of the basal fluorescence intensity at time 0 . Cells were challenged with $100 \mathrm{nM}$ LPA and $100 \mu M$ UTP at the times indicated by the horizontal bars beneath the graphs. a-d indicate the times of capture of the images shown in A. (C) Peak amplitudes of $\mathrm{Ca}^{2+}$ responses to LPA and UTP were calculated. Data are the maximum elevation above basal expressed as a percentage of basal. VPC-32183 significantly suppressed the $\mathrm{Ca}^{2+}$ response induced by 100 nM LPA (left) but had no effect on the subsequent response to UTP (right). Data are means \pm SEM $(n=3$ independent preparations). *, significant effect of VPC32183 compared with vehicle $(P<0.05)$. approach to directly investigate whether $\mathrm{P} 2 \mathrm{X} 7$ receptor activation leads to the production of LPA. Rat calvarial cells were labeled with $\left[{ }^{14} \mathrm{C}\right]$ glycerol overnight and then incubated with $300 \mu \mathrm{M}$ BzATP or vehicle (control) for $20 \mathrm{~min}$. Cells were collected and total lipids were separated using thin layer chromatography (Fig. 6 A). BzATP induced a significant increase in levels of phosphatidic acid (PA; Fig. 6 B, top). The phospholipase D (PLD) inhibitor 1-butanol (1\% vol/vol) completely inhibited the production of phosphatidic acid induced by BzATP. In contrast, its inactive analogue tert-butanol had little effect. Moreover, $10 \mu \mathrm{M}$ of the $\mathrm{PLA}_{2}$ inhibitor bromoenol lactone (BEL) had no significant effect on phosphatidic acid synthesis. Importantly, BzATP stimulated production of LPA (Fig. 6 B, middle). This effect was abolished by 1-butanol as well as by BEL, whereas tert-butanol had no significant effect. In the absence of phospholipase inhibitors, BzATP caused a significant decrease in levels of phosphatidylcholine (PC, Fig. $6 \mathrm{~B}$, bottom), which is consistent with phosphatidylcholine being a preferred substrate of PLD (Frohman et al., 1999). In accord, there were no significant changes in phosphatidylethanolamine levels (Fig. S2, available at http://www.jcb.org/cgi/content/full/jcb.200708037/DC1).

As in rat calvarial cells, BzATP stimulated production of LPA in wild-type murine cells (Fig. $6 \mathrm{C}$, left), together with a corresponding decrease in phosphatidylcholine levels (Fig. $6 \mathrm{C}$, right). In contrast, BzATP failed to induce LPA production in cells from $P 2 r x 7^{-/-}$mice. These data establish directly that activation of $\mathrm{P} 2 \mathrm{X} 7$ receptors leads to production of the potent lipid mediator LPA through stimulation of PLD and PLA 2 activity.

\section{Role of lipid signaling pathways in mediating BzATP-induced osteogenesis}

LPA acts through the specific $G$ protein-coupled receptors LPA1-5. LPA1 is widely distributed and appears to be the predominant receptor subtype present in cells of the osteoblast lineage (Masiello et al., 2006). We tested directly whether LPA signaling is involved in P2X7-induced osteogenesis.

We began by assessing the effectiveness and specificity of the LPA1/3 receptor antagonist VPC-32183 (Heasley et al., 2004) in rat calvarial cell cultures. Because LPA receptors signal through PLC (Mills and Moolenaar, 2003), we monitored LPA-induced elevation of $\left[\mathrm{Ca}^{2+}\right]_{\mathrm{i}}$ (cytosolic free $\mathrm{Ca}^{2+}$ concentration). When cells were loaded with fluo-4 and monitored using confocal microscopy, $100 \mathrm{nM}$ LPA was found to induce a transient increase in $\left[\mathrm{Ca}^{2+}\right]_{\mathrm{i}}$ (Fig. 7 A). Subsequent stimulation with $100 \mu \mathrm{M}$ UTP caused a similar increase in $\left[\mathrm{Ca}^{2+}\right]_{\mathrm{i}}$ because of activation of P2Y receptors, which also couple through G proteins to PLC. $1 \mu \mathrm{M}$ VPC-32183 suppressed the $\mathrm{Ca}^{2+}$ response to LPA without affecting the UTP response (Fig. 7 B), indicating specificity of this antagonist for LPA receptors. Quantification of peak amplitudes revealed that the LPA-induced $\mathrm{Ca}^{2+}$ response was virtually abolished by VPC-32183 (Fig. 7 C, left), whereas VPC-32183 did not affect the UTP-induced elevation of $\left[\mathrm{Ca}^{2+}\right]_{\mathrm{i}}$ (Fig. $7 \mathrm{C}$, right). 

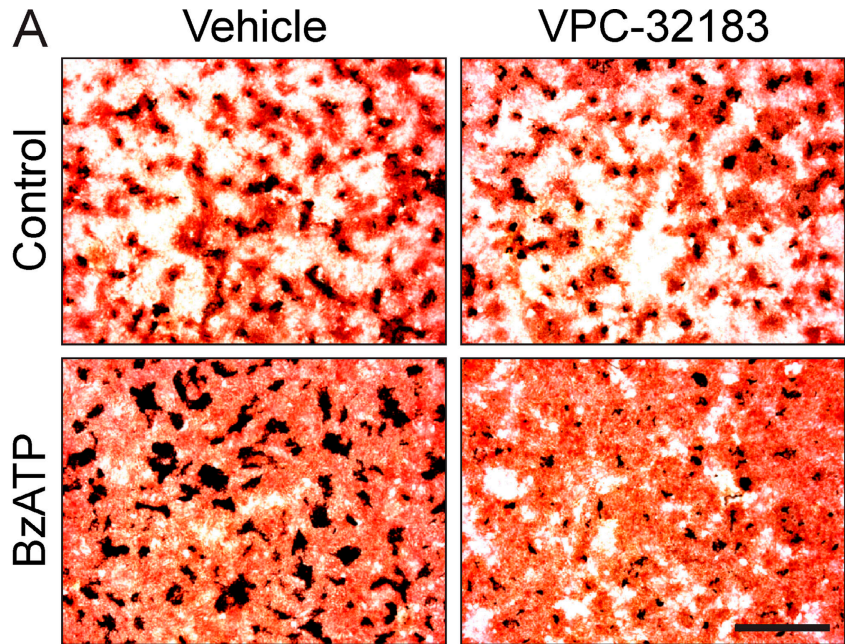

B 15
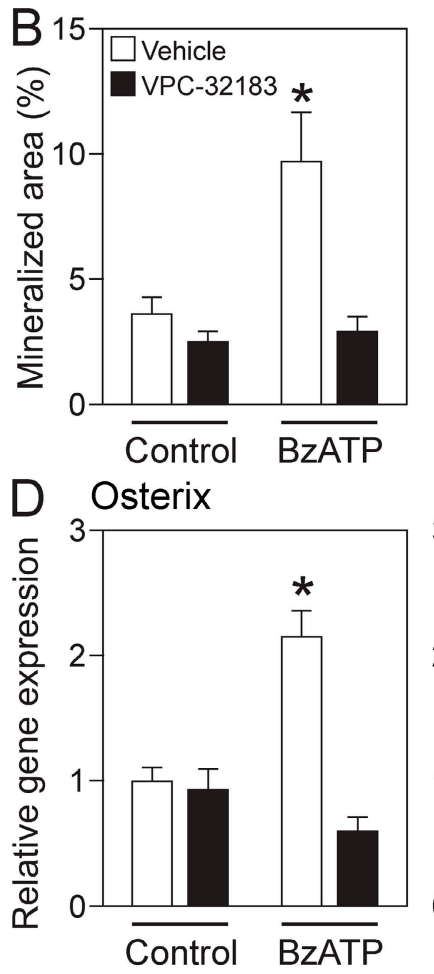
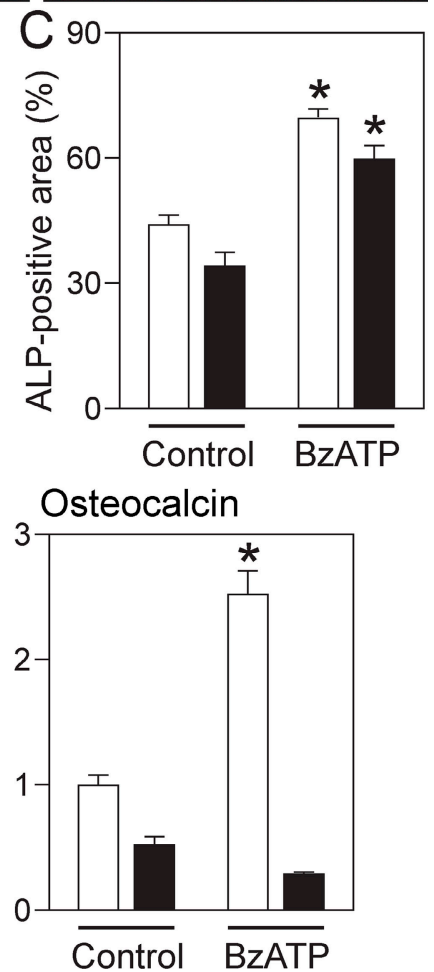

Figure 8. VPC-32183 suppresses BzATP-enhanced mineralization. During differentiation, rat calvarial cells were treated with 1 pM VPC-32183 or its vehicle and $100 \mu \mathrm{M} \mathrm{BzATP}$ or its vehicle (control) for $14 \mathrm{~d}$. (A) Cultures were fixed and stained for ALP activity and mineral deposition. Bar, $1 \mathrm{~mm}$. (B) VPC-32183 suppressed BzATP-enhanced mineralization without significantly affecting control cultures. (C) ALP activity was not significantly affected by VPC-32183. (D) Expression levels of genes encoding osterix and osteocalcin were analyzed using real-time RT-PCR. Data are expressed relative to values in vehicle-treated control cultures. VPC-32183 abolished the effects of BzATP on osterix and osteocalcin expression. Data are means \pm SEM ( $n=3$ independent preparations). ${ }^{*}$, significant effect of BzATP compared with control $(P<0.05)$.

Having demonstrated the effectiveness and specificity of VPC-32183 in osteoblasts, we next investigated the effects of this LPA receptor antagonist on BzATP-induced osteogenesis. Rat calvarial cells were differentiated with or without $100 \mu \mathrm{M}$ BzATP, and cultures were also treated with $1 \mu \mathrm{M}$ VPC-32183 or its vehicle for $14 \mathrm{~d}$. As expected, BzATP enhanced mineralization and ALP activity. Importantly, VPC-32183 abolished the effect of

BzATP on mineral deposition (Fig. 8, A and B). In contrast, the LPA receptor antagonist had only a modest effect on the BzATPinduced increase in ALP activity (Fig. 8, A and C). In addition, VPC-32183 itself had no effect on cell numbers (Fig. S3 A, available at http://www.jcb.org/cgi/content/full/jcb.200708037/DC1). In some experiments, total RNA was collected and real-time RTPCR analysis was performed. VPC-32183 abolished the increase in expression of osterix and osteocalcin induced by BzATP (Fig. 8 D). These data indicate that BzATP-induced osteogenesis is dependent on pathways downstream of LPA receptors.

It is possible that BzATP-induced osteogenesis involves signaling pathways in addition to LPA. Activation of $\mathrm{PLA}_{2}$ leads to production of eicosanoids such as prostaglandin $\mathrm{E}_{2}\left(\mathrm{PGE}_{2}\right)$, which is known to stimulate bone formation in vitro and in vivo (Flanagan and Chambers, 1992; Yoshida et al., 2002). Therefore, we determined the effects of BzATP on synthesis of $\mathrm{PGE}_{2}$. After $5 \mathrm{~min}, 300 \mu \mathrm{M}$ BzATP significantly increased $\mathrm{PGE}_{2}$ release from rat calvarial cell cultures (Fig. 9 A). $10 \mu \mathrm{M}$ ibuprofen, which inhibits both COX-1 and -2 , blocked the effects of BzATP on $\mathrm{PGE}_{2}$ synthesis. In contrast, VPC-32183 did not inhibit $\mathrm{PGE}_{2}$ production ( $n=3$ independent experiments; unpublished data), indicating that BzATP-induced prostaglandin synthesis does not depend on LPA receptor activation.

We next explored the role of COX in P2X7-induced osteogenesis. Rat calvarial cells were differentiated with or without $100 \mu \mathrm{M}$ BzATP, and in the presence of $10 \mu \mathrm{M}$ ibuprofen, $10 \mu \mathrm{M}$ NS-398 (a selective COX-2 inhibitor), or vehicle for $14 \mathrm{~d}$. Like VPC-32183, NS-398 itself had no effect on cell numbers (Fig. S3 B). Again, BzATP stimulated mineralization and ALP activity (Fig. 9 B). Similar to the actions of VPC-32183, COX inhibitors abolished the effects of BzATP on mineralization and osteocalcin expression while only slightly suppressing ALP activity (Fig. 9, C-E). Activation of $\mathrm{P} 2 \mathrm{X} 7$ receptors did not significantly alter expression of COX-2 at $14 \mathrm{~d}$ (mRNA levels in BzATPtreated cells were $122 \pm 5 \%$ of control; $n=3$ independent experiments; P > 0.05). However, it is possible that BzATP transiently alters COX-2 expression at earlier times. Collectively, these data implicate eicosanoid signaling along with LPA in mediating P2X7-induced osteogenesis (Fig. 10).

\section{Discussion}

P2X7 receptors promote osteogenesis in vivo and in vitro

Mesenchymal cells within cranial sutures proliferate and differentiate to sustain the osteoblast population and form new bone (Morriss-Kay and Wilkie, 2005), processes which are stimulated at least in part by mechanical tension (Hou et al., 2007). In the present study, microcomputed tomography revealed wider sutures in adult $P 2 r x 7^{-/-}$mice compared with the wild type, which is consistent with reduced osteogenesis at the suture. In contrast, there was no apparent difference in the size of fontanelles of wild-type and $P 2 r x 7^{-/-}$mice at birth (unpublished data), although $\mathrm{P} 2 \mathrm{X} 7$ receptors are expressed in the cranial bones and vertebrae of embryonic day 19 rat embryos (Collo et al., 1997). This phenotype is in keeping with the characteristics of long bones in $P 2 r x 7^{-/-}$mice, which display reduced periosteal 

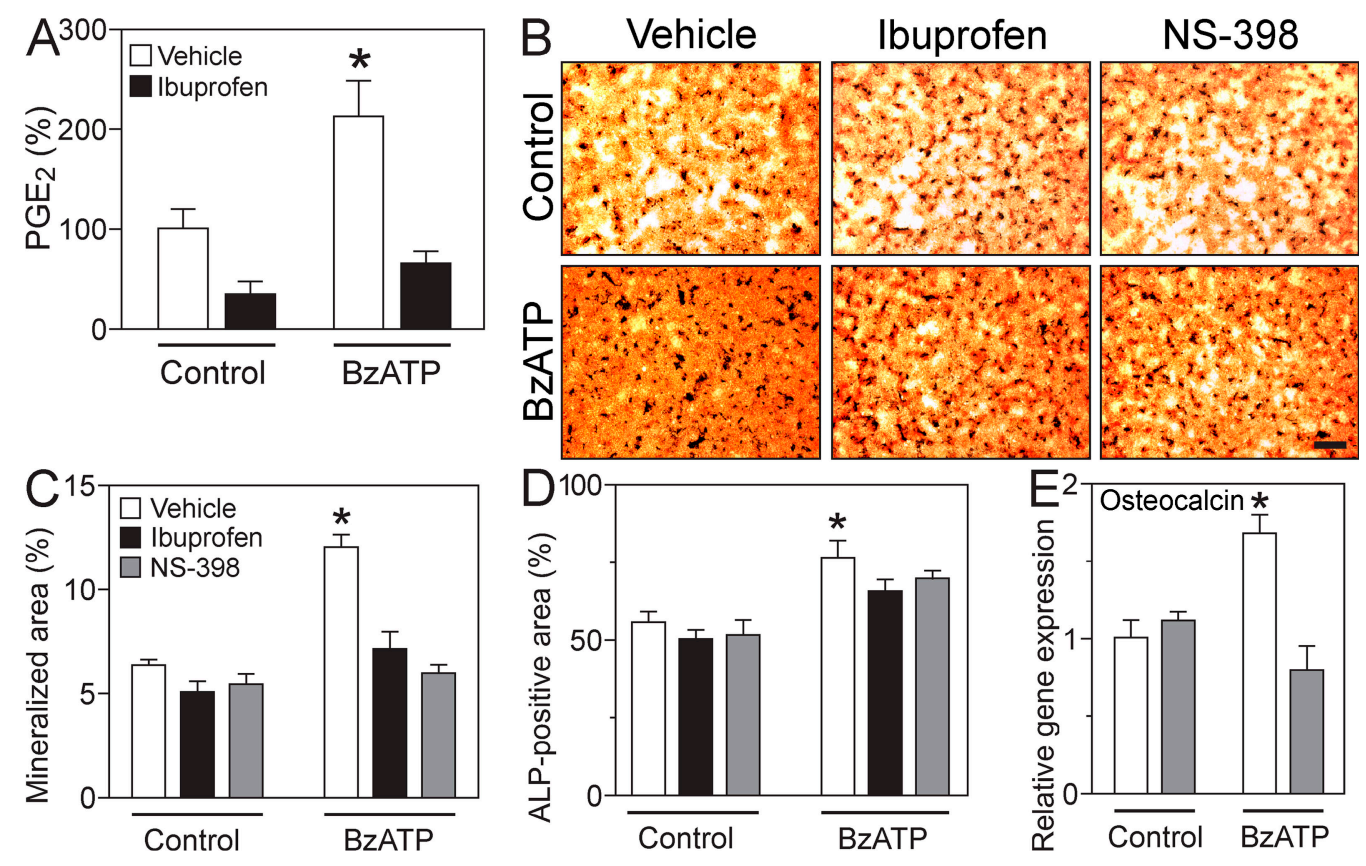

Figure 9. COX inhibitors suppress BzATP-enhanced mineralization in rat calvarial cell cultures. (A) Rat calvarial cells were incubated in serum-free medium for $15-18 \mathrm{~h}$ and then treated for $10 \mathrm{~min}$ at $37^{\circ} \mathrm{C}$ with $10 \mu \mathrm{M}$ ibuprofen (COX inhibitor) or vehicle. $300 \mu \mathrm{M} \mathrm{BzATP}$ or its vehicle (control) was then added and cultures were incubated for an additional $5 \mathrm{~min}$. Media were collected and levels of $\mathrm{PGE}_{2}$ assessed. Data are expressed as percentages of PGE levels in vehicle-treated control. * , significant effect of BzATP compared with corresponding control $(\mathrm{P}<0.05 ; n=3$ independent preparations). (B) During differentiation, rat calvarial cells were treated with $10 \mu$ M ibuprofen, $10 \mu \mathrm{M}$ NS-398 (COX-2 inhibitor), or vehicle and also with $100 \mu \mathrm{M} \mathrm{BzATP}$ or its vehicle (control) for $14 \mathrm{~d}$. Cultures were fixed and stained for ALP activity and mineral deposition. Bar, $1 \mathrm{~mm}$. (C and D) Ibuprofen and NS-398 abolished the effects of BzATP on mineralization (C) and moderately suppressed ALP activity (D). (E) Osteocalcin expression was quantified by real-time RT-PCR. Data are expressed relative to values in vehicle-treated control. NS-398 abolished the effect of BzATP on osteocalcin expression. Data are means \pm SEM $(n=3$ independent preparations). ${ }^{*}$, significant effect of BzATP compared with control $(P<0.05)$.

circumference which is more evident in adult $(9 \mathrm{mo})$ than young (2 mo) mice (Ke et al., 2003). The late onset of differences between the skeletons of $P 2 r x 7^{-/-}$and wild-type mice is consistent with a role for $P 2 r x 7$ in mechanically stimulated bone remodeling rather than in development per se.

We identified functional $\mathrm{P} 2 \mathrm{X} 7$ receptors in cells of the osteoblast lineage in situ. This finding rules out the possibility that receptor expression is induced by in vitro culture, as reported previously for $\mathrm{P} 2 \mathrm{Y} 2$ receptors in cells from rat submandibular salivary gland (Turner et al., 1997). Functional P2X7 receptors were present in cells located on the ectocranial surface of calvariae, which undergoes active osteogenesis during cranial expansion. In vitro, $\mathrm{P} 2 \mathrm{X} 7$ receptors are expressed in a subpopulation of calvarial cells and bone marrow stromal cells. Interestingly, calvarial cells expressing functional $\mathrm{P} 2 \mathrm{X} 7$ receptors were associated with bone-like nodules, which is consistent with their expression in differentiated osteoblasts and with a role for these receptors in osteogenesis.

In addition to effects mediated by $\mathrm{P} 2 \mathrm{X} 7$ receptors, nucleotides may regulate osteogenesis via interactions with other P2 receptor subtypes as well as by providing a source of $\mathrm{P}_{\mathrm{i}}$ (which promotes mineralization) and pyrophosphate (which inhibits mineralization). Thus, effects of nucleotides on osteoblasts likely differ depending on which $\mathrm{P} 2$ receptor subtypes are activated. At concentrations too low to activate $\mathrm{P} 2 \mathrm{X} 7$ receptors but sufficient to activate several other P2 receptor subtypes, ATP stimulates the proliferation of osteoblast-like cells (Shimegi, 1996;
Nakamura et al., 2000) and activates the early growth response protein Egr-1 (Pines et al., 2003). Moreover, ATP and UTP at low concentrations have been reported to inhibit bone nodule formation by rat calvarial osteoblasts (Hoebertz et al., 2002), an effect which is mediated by $\mathrm{P} 2 \mathrm{Y} 2$ receptors and the release of pyrophosphate (Orriss et al., 2007).

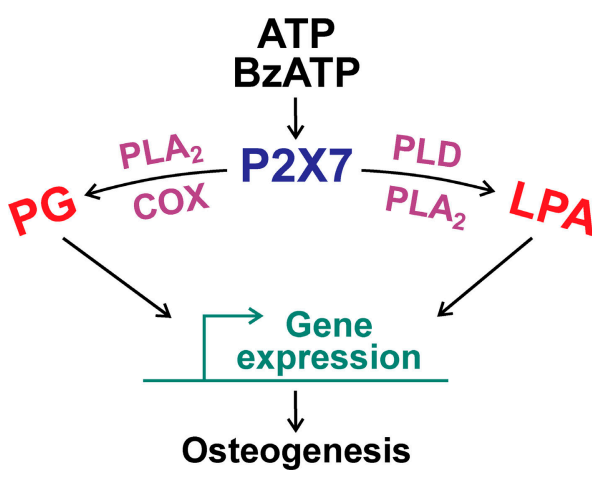

Figure 10. Proposed P2X7-LPA signaling axis promoting osteogenesis. Activation of P2X7 receptors on cells of the osteoblast lineage by endogenous ATP or exogenous BzATP leads to production of LPA through a pathway involving PLD and PLA 2 . In addition, activation of $\mathrm{PLA}_{2}$ leads to production of COX metabolites such as prostaglandins (PG). LPA and prostaglandins then bind to their receptors on the same or neighboring cells to induce expression of osteoblast genes such as osterix and osteocalcin. Up-regulation of these genes in turn induces osteogenesis by promoting differentiation and mineralization. 
Regulation of gene expression by $P 2 \times 7$ receptors during osteogenesis

Characterization of mice lacking genes encoding Runx 2 and osterix has established the roles of these transcription factors as master regulators of osteoblast differentiation (Ducy et al., 1997; Nakashima et al., 2002). Run $x 2^{-/-}$mice also exhibit a defect in the differentiation of hypertrophic chondrocytes (Enomoto et al., 2000). We found that there was significant reduction in osterix, but not Runx2, mRNA in calvarial cell cultures from $P 2 r x 7^{-/-}$ mice compared with the wild type. Runx 2 functions upstream of osterix and can directly regulate its expression (Nishio et al., 2006). Thus, it is likely that $\mathrm{P} 2 \mathrm{X} 7$ receptors up-regulate expression of osterix and promote osteoblast differentiation downstream of Runx 2 or via effects on Runx 2 activity that can be regulated by phosphorylation (Ge et al., 2007). Moreover, in $P 2 r x 7^{-1-}$ calvarial cell cultures, we observed down-regulation of the gene encoding osteocalcin, which is known to be regulated by osterix (Nakashima et al., 2002).

We found that deletion of P2rx7 not only suppresses osteoblast differentiation but enhances expression of the adipocyte markers PPAR $\gamma$ and lipoprotein lipase. Bipotential mesenchymal cells can differentiate into cells of the osteoblast or adipocyte lineage depending on levels of osterix and PPAR $\gamma$ expression (Ali et al., 2005). Thus, it appears that activation of P2X7 receptors directs cells toward the osteoblast lineage. Like Runx2 and osterix in osteoblasts, Sox 9 regulates chondrocyte differentiation through activation of several genes including Col2al (Lefebvre et al., 1997). We found that there was no significant difference in Sox 9 and Col2al expression in calvarial cells from $P 2 r x 7^{-1-}$ compared with wild-type mice at any time during differentiation. It has been shown that Sox9 in embryonic osteochondroprogenitor cells regulates both intramembranous and endochondral ossification; however, expression of Sox 9 precedes that of Runx2 and osterix (Akiyama et al., 2005). Collectively, P2X7 receptors appear to regulate osteogenesis at a stage later than Sox9 induction, which is consistent with the skeletal phenotype of the $P 2 r x 7^{-1-}$ mouse in which long bone length and presumably chondrocyte differentiation are unaffected (Ke et al., 2003).

The role of lipid signaling pathways in P2X7-induced osteogenesis

In the present study, we have shown directly that BzATP induces production of phosphatidic acid (via activation of PLD) and LPA (via activation of PLD and PLA $\mathrm{A}_{2}$ ) in osteoblasts. LPA is a soluble mediator that acts on $\mathrm{G}$ protein-coupled receptors, five of which, LPA1-5, are currently identified in mammals (Anliker and Chun, 2004; Lee et al., 2006). LPA binds to its receptors on cells of the osteoblast lineage and subserves many functions, such as promoting proliferation, inducing migration, and regulating morphology (Grey et al., 2001; Masiello et al., 2006; Panupinthu et al., 2007).

It is possible that the role of LPA in osteogenesis has not been recognized previously because LPA is abundant in serum used to supplement media for in vitro bone formation assays. Moreover, production of LPA may explain previous reports of apparently anomalous responses to $\mathrm{P} 2 \mathrm{X} 7$ receptor activation in other systems. For example, heterologous expression of P2X7 receptors in lymphoid and other cell types confers the ability to grow in the absence of serum (Baricordi et al., 1999; Adinolfi et al., 2005), possibly because of the production of LPA.

Activation of PLA 2 is a key step in the production of LPA as well as the formation of eicosanoids. In the present study, we showed that the COX pathway is involved in P2X7-induced osteogenesis in concert with LPA receptor signaling. In keeping with our findings, bone marrow-derived osteoblasts exhibit reduced osterix expression in the absence of the gene encoding COX-2 (Zhang et al., 2002). Interestingly, mechanically induced release of $\mathrm{PGE}_{2}$ is impaired in osteoblasts from $P 2 r x 7^{-1-}$ mice (Li et al., 2005). Moreover, release of ATP in response to mechanical stimulation leads to the production of $\mathrm{PGE}_{2}$ in MC3T3-E1 osteoblastic cells (Genetos et al., 2005).

Based on our pore formation and receptor expression studies, it appears that differentiated cells of the osteoblast lineage express functional $\mathrm{P} 2 \mathrm{X} 7$ receptors. However, studies of marker gene expression indicated that these receptors regulate the differentiation of less mature cells. In this regard, LPA and eicosanoids produced in response to activation of $\mathrm{P} 2 \mathrm{X} 7$ receptors on mature osteoblasts may act as autocrine factors on the same cells. In addition, these mediators could act as paracrine factors to stimulate the differentiation of less mature cells in the surrounding region. Collectively, we have identified two lipid signaling pathways, involving LPA and eicosanoids, underlying P2X7-induced osteogenesis.

\section{Physiological relevance of $\mathrm{P} 2 \times 7$-induced osteogenesis}

ATP is released from bone cells in vitro through constitutive and inducible mechanisms (Buckley et al., 2003; Genetos et al., 2005). In $P 2 r x 7^{-1-}$ mice, osteogenesis (Ke et al., 2003) and anabolic responses to mechanical loading ( $\mathrm{Li}$ et al., 2005) are impaired, indicating that release of ATP into the bone extracellular fluid occurs in vivo. Our present data are consistent with release of endogenous ATP stimulating osteogenesis in vitro. In this regard, it has been shown that the differentiation of rat calvarial cells is accompanied by a fivefold increase in cytosolic ATP content at 10-14 d (Komarova et al., 2000). However, the concentration of ATP in the extracellular compartment depends upon the balance between the release of ATP and its degradation by ectonucleotidases. Therefore, it is conceivable that constitutive ATP release in vivo is insufficient to activate $\mathrm{P} 2 \mathrm{X} 7$ receptors, whereas enhanced release arising from mechanical stimulation is sufficient to trigger $\mathrm{P} 2 \mathrm{X} 7$ signaling.

In keeping with a role for $\mathrm{P} 2 \mathrm{X} 7$ in mechanotransduction, differences in osteogenesis in $P 2 r x 7^{-/-}$mice are most noticeable at sites in long bones that experience large mechanical strain caused by weight bearing (Ke et al., 2003). It is known that osteogenesis on periosteal surfaces correlates with applied stress (Robling et al., 2006). In this paper, we characterized an additional defect in the $P 2 r x 7^{-/-}$mouse involving impaired sutural bone growth. Tensile forces caused by intracranial pressure are thought to trigger the growth of bone at sutures (Hou et al., 2007). Therefore, it is possible that mechanical strain induces local release of ATP, which then activates $\mathrm{P} 2 \mathrm{X} 7$ receptors on cells of osteoblast lineage, inducing osteogenesis. 
In summary, we propose that the P2X7-LPA axis, together with eicosanoid signaling, promotes osteogenesis. It is well established that release of the endogenous P2X7 agonist ATP is stimulated by fluid shear and mechanical deformation of cells (Romanello et al., 2001; Genetos et al., 2005; Riddle et al., 2007). Thus, the P2X7-LPA axis likely plays a critical role in skeletal remodeling and mechanotransduction.

\section{Materials and methods}

\begin{abstract}
Materials
$\alpha-M E M$, heat-inactivated FBS, antibiotic solution $(10,000$ units $/ \mathrm{ml}$ penicillin, $10,000 \mu \mathrm{g} / \mathrm{ml}$ streptomycin, and $25 \mu \mathrm{g} / \mathrm{ml}$ amphotericin B), PBS, TRIZOL reagent, SYTO-13, propidium iodide, HOECHST 33342, fluo-4$\mathrm{AM}$, and Pluronic F1 27 were obtained from Invitrogen. Nucleotides, collagenase type II, naphthol AS-MX phosphate, Fast Red B salt, ibuprofen, and LPA (1-oleoyl-sn-glycero-3-phosphate) were purchased from Sigma-Aldrich. 1-Butanol, NS-398, and ethidium bromide were obtained from EMD. tertButanol was obtained from Thermo Fisher Scientific. BEL was obtained from BIOMOL International, L.P. [U- $\left.{ }^{14} \mathrm{C}\right]$ Glycerol was obtained from PerkinElmer. VPC-32183 and reference membrane lipids, including 16:0-18:1 phosphatidylcholine, 16:0 lysophosphatidylcholine, 16:0-18:1 phosphatidic acid, 16:0 LPA, 16:0-18:1 phosphatidylethanolamine, 16:0-18:1 phosphatidylglycerol, and 16:0 lysophosphatidylglycerol were obtained from Avanti Polar Lipids, Inc. Stock solutions of LPA and VPC-32183 were prepared in $3 \% \mathrm{BSA}$ and aliquots were stored at $-20^{\circ} \mathrm{C}$. Nominally divalent cation-free buffer contained the following: $140 \mathrm{mM} \mathrm{NaCl}, 5 \mathrm{mM} \mathrm{KCl}$, $20 \mathrm{mM} \mathrm{Na}$-Hepes, and $10 \mathrm{mM}$ glucose, pH $7.35 \pm 0.02,290 \pm 5$ mos$\mathrm{mol} / \mathrm{L}$. For short-term experiments, we used BzATP in buffer at $300 \mu \mathrm{M}$, a concentration which we have previously shown to induce maximal blebbing activity in calvarial osteoblasts (Panupinthu et al., 2007). For longterm experiments, we used $100 \mu \mathrm{M}$ BzATP in medium ( $\left.\mathrm{EC}_{50}\right)$ to minimize possible nonspecific effects.
\end{abstract}

\section{Animals}

The $P 2 r x 7^{-1-}$ mouse, generated as described previously (Solle et al., 2001), was obtained from Pfizer. Both wild-type and $P 2 r \times 7^{-1-}$ mice were maintained in a mixed genetic background (129/Ola $\times$ C57BL/ $6 \times$ DBA/2) by crossbreeding of $P 2 r \times 7^{+1-}$ mice. Genotypes were confirmed using PCR. Sprague-Dawley rats were purchased from Charles River Laboratories. These studies were approved by the Council on Animal Care at the University of Western Ontario.

\section{Microcomputed tomography}

Male and female wild-type and $P 2 r \times 7^{-1-}$ mice were killed at 9 mo of age. Skin and viscera were removed and specimens fixed in $10 \%$ formalin solution. Skulls together with synthetic bone (SB3) for calibration were imaged using a scanner (eXplore Locus MicroCT; GE Healthcare). Each skull was exposed to the $x$-ray source with a potential of $80 \mathrm{kV}$ and a current of 0.45 $\mathrm{mA}$ at a rate of three frames per $2 \mathrm{~s}$ for each angle. X-ray images were acquired at an angular increment of $0.5^{\circ}$ and a $360^{\circ}$ rotation. Data were obtained with isotropic spatial resolution of $40 \mu \mathrm{m}$ and reconstructed using Feldkamp's algorithm. Calvarial thickness and cross sectional area of the sagittal suture were analyzed using MicroView software (GE Healthcare).

\section{In situ pore formation assay and confocal microscopy}

Calvariae were excised from newborn wild-type and $P 2 r \times 7^{-1-}$ mice. Each parietal bone was trimmed to obtain an $\sim 3 \times 3-\mathrm{mm}$ sample. At time 0 , samples were incubated at $37^{\circ} \mathrm{C}$ in nominally divalent cation-free buffer At $10 \mathrm{~min}$, BzATP or its vehicle was added. At $20 \mathrm{~min}, 5$ M SYTO- 13 and $20 \mathrm{\mu g} / \mathrm{ml}$ ethidium bromide were added to stain nuclei and reveal pore formation, respectively. At $22 \mathrm{~min}$, samples were washed and images acquired by confocal microscopy (LSM 510; Carl Zeiss, Inc.) using a PlanApochromat objective (25x;0.8 NA; Carl Zeiss, Inc.). We used 488-nm $\mathrm{Ar}^{+}$ion laser excitation with a 500-530-nm band-pass emission filter for SYTO-13 and 543-nm HeNe laser excitation with a 560-nm long-pass emission filter for ethidium bromide. Images were collected and analyzed using LSM 510 software (Carl Zeiss, Inc.).

\section{Osteoblast isolation and differentiation}

Calvarial cells were isolated from 1-d-old rats and 5-7-d-old mice using sequential collagenase digestion, as previously described (Bellows and Aubin, 1989) with modifications. Because larger yields of cells were obtained from rats and the system has been extensively characterized, rat cultures were used for most experiments. Cells from wild-type and $P 2 r x 7^{-1-}$ mice were used to assess the effect of P2X7 loss-of-function on osteogenesis. For rat cultures, freshly isolated calvarial cells were plated in T-25 flasks at a density of $1.5 \times 10^{4}$ cells $/ \mathrm{cm}^{2}$ and maintained in $\alpha$-MEM with $10 \%$ FBS and $1 \%$ antibiotic solution (culture medium). After $3 d$, undifferentiated cultures were trypsinized and seeded on six-well plates at a density of $3 \times 10^{4}$ cells $/ \mathrm{cm}^{2}$. After an additional $3 \mathrm{~d}$, culture medium was supplemented with $50 \mathrm{\mu g} / \mathrm{ml}$ ascorbic acid and $2 \mathrm{mM}$ $\beta$-glycerophosphate (defined as day 0). Cells were cultured for up to 4 wk (day 28) together with test substances or vehicles in supplemented medium, which was changed every 2-3 d. In some experiments, bone marrow stromal cells were obtained from femurs and tibias of 1 -d-old rats as previously described (Maniatopoulos et al., 1988).

For murine cultures, freshly isolated calvarial cells were seeded on six-well plates at a density of $1.5 \times 10^{4} \mathrm{cell} / \mathrm{s} / \mathrm{cm}^{2}$ in culture medium. After $3 \mathrm{~d}$, cells were trypsinized and transferred to 12 -well plates, with each well

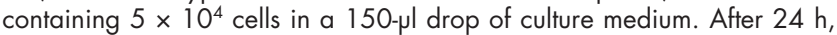
culture medium was added to the micromasses. After an additional $2 \mathrm{~d}$, cultures were supplemented with $50 \mathrm{\mu g} / \mathrm{ml}$ ascorbic acid and $2 \mathrm{mM}$ $\beta$-glycerophosphate and maintained for up to $28 \mathrm{~d}$.

\section{In vitro pore formation assay}

Rat calvarial cells were isolated and plated in culture medium on a two-well Lab-Tek Chamber Slide (Thermo Fisher Scientific) at a density of $3 \times 10^{4}$ cells $/ \mathrm{cm}^{2}$. Cultures were differentiated with ascorbic acid and $\beta$-glycerophosphate for 14-21 d. Some experiments were also performed using undifferentiated cells isolated from long bones of newborn rats. Pore formation assay was performed in nominally divalent cation-free buffer with BzATP or its vehicle as described in In situ pore formation assay and confocal microscopy. In vitro studies were performed using propidium iodide rather than ethidium bromide.

\section{Cytochemical analyses of ALP activity and mineral deposition}

Calvarial cell cultures were fixed with $4 \%$ neutral buffered formalin overnight at $4^{\circ} \mathrm{C}$. ALP activity was revealed using a mixture of $0.25 \mathrm{mM}$ naphthol AS-MX phosphate and $1.25 \mathrm{mM}$ Fast Red B salt in $0.1 \mathrm{M}$ Tris-HCl, $\mathrm{pH} 8$, for $1 \mathrm{~h}$ in the dark. To demonstrate mineral deposition, the same cultures were stained with $2.5 \% \mathrm{wt} / \mathrm{vol}$ silver nitrate solution (von Kossa staining) for $1 \mathrm{~h}$ with exposure to light. Images of rat calvarial cell cultures were captured using a microscope (SMZ1500; Nikon) with Plan APO objective (0.1 NA) attached to a charge-coupled device camera (CoolSNAP; Roper Scientific). Mineralized and ALP-positive areas were quantified from four fields per well. Images of murine calvarial cell cultures were captured using a scanner (Perfection 1650; Epson). Mineralized and ALP-positive areas were quantified from the entire well. Sizes of acquisition fields and color balance were standardized and 2D images were analyzed using Image Master software (Photon Technology International).

\section{RT-PCR analyses}

For real-time RT-PCR analyses, total RNA was isolated from differentiated calvarial cell cultures at 7-d intervals using TRIZOL reagent and the RNeasy Mini kit (QIAGEN). Primer and probe sequences for genes encoding Runx2 (Runx2), osterix (Sp7), bone sialoprotein (lbsp), osteocalcin (Bglap 1), Sox9 (Sox9), and collagen type II $\alpha 1$ (Col2al) were designed using PrimerDesigner software (Applied Biosystems; Table S1, available at http://www.jcb.org/cgi/content/full/jcb.200708037/DC1). Primers and probes for P2X7 (P2rx オ, PPAR (Pparg), lipoprotein lipase (Lp)), and COX-2 (Ptgs2) were purchased from Applied Biosystems (Gene Expression Assay). Real-time RT-PCR was performed using the ABI Prism 7900 HT Sequence Detector (PerkinElmer) with 15- $\mu$ l final reaction volumes, which contained a 25-ng RNA sample, TaqMan One-step Master Mix kit (Applied Biosystems), and gene-specific target primers and probes (FAM dye). Internal control reaction was performed using $18 \mathrm{~S}$ ribosomal RNA primers and probes (VIC dye). Reverse transcription was performed at $48^{\circ} \mathrm{C}$ for $30 \mathrm{~min}$. Amplification was performed for 40 cycles with an annealing temperature of $60^{\circ} \mathrm{C}$. All samples were amplified in three parallel reactions. Data from serial dilution of total RNA were used to calculate relative quantities of transcripts of interest and 18S ribosomal RNA. Transcript levels were normalized to levels of $18 \mathrm{~S}$ ribosomal RNA in the same samples.

For conventional RT-PCR analysis of $P 2 r x 7$ expression, total RNA was extracted from undifferentiated cultures of cells isolated from rat calvariae and long bones, as well as the UMR-106 osteoblast-like cell line (negative control). RT-PCR was performed as described previously (Dixon et al., 2004). Images of gels were acquired using an Alphalmager 2200 (Alpha Innotech Corporation) with a zoom lens (Computar TV; 1.2 NA; CBC (AMERICA) Corporation). 


\section{DNA assay}

To label DNA, osteoblasts were loaded with $5 \mu \mathrm{g} / \mathrm{ml} \mathrm{HOECHST} 33342$ for $30 \mathrm{~min}$ in culture medium at $37^{\circ} \mathrm{C}$. Cells were trypsinized and fluorescence intensity of samples from each well was measured using a fluorimeter (RF-M2004; Photon Technology International) with excitation at $350 \mathrm{~nm}$ and emission at $450 \mathrm{~nm}$.

\section{Extraction of lipids and thin layer chromatography}

Calvarial cells were isolated from newborn rats or mice (wild type and $P 2 r \times 7^{-1-}$ ) and labeled with $1 \mu \mathrm{Ci} / \mathrm{ml}\left[{ }^{14} \mathrm{C}\right]$ glycerol in serum-free $\alpha-M E M$ for $18 \mathrm{~h}$. Medium containing unincorporated radiolabel was then replaced with nominally divalent cation-free buffer at $37^{\circ} \mathrm{C}$ containing inhibitors or vehicle. After $10 \mathrm{~min}, \mathrm{BzATP}$ or its vehicle (control) was added. After a further $20 \mathrm{~min}$, buffer was removed and lipids were extracted from the cell layer (Bligh and Dyer, 1959). Extracts were dried under a stream of $\mathrm{N}_{2}$ and dissolved in chloroform together with the reference membrane lipids. Silica gel plates (LK4D; Whatman) were sprayed with a solution of $0.05 \mathrm{M}$ magnesium acetate and $0.35 \mathrm{M}$ oxalic acid. After plates were dried, samples were loaded and separated by thin layer chromatography using the following solvent system (by volume): 34:30:35:6.5 ethanol/chloroform/ triethylamine/water. After chromatography, plates were sprayed with $0.1 \mathrm{mM}$ primulin in $80 \%$ acetone and examined under UV light. Regions of silica gel defined by reference lipids were collected and radioactivity was quantified by liquid scintillation counting. Images of reference lipids were acquired using Polaroid MP-4+ camera system (4.5 NA; Polaroid) with UV illumination.

\section{Fluorescence measurement of $\left[\mathrm{Ca}^{2+}\right]_{i}$}

Undifferentiated calvarial cells were plated on 35-mm glass bottom culture dishes (MatTek Corporation) at a density of $3 \times 10^{4} \mathrm{cells} / \mathrm{cm}^{2}$ for $24 \mathrm{~h}$. Cells were loaded by incubation with $2.5 \mu \mathrm{M}$ fluo-4-AM and $0.1 \%$ Pluronic F127 in serum-free $\alpha-M E M$ for 30 min at $37^{\circ} \mathrm{C}$. Cultures then were washed with serum-free medium, incubated with VPC-32183 or vehicle, and examined by confocal microscopy at room temperature using a Plan-Apochromat $40 \times$ objective (1.2 NA; Carl Zeiss, Inc.) with 488-nm $\mathrm{Ar}^{+}$ion laser excitation. Emission wavelength was gathered using a 500-530-nm band-pass filter. Fluorescence intensity was analyzed using LSM 510 software.

\section{$\mathrm{PGE}_{2}$ assay}

Rat calvarial cells were incubated in serum-free $\alpha-M E M$ at $37^{\circ} \mathrm{C}$ for $18 \mathrm{~h}$. Medium was then replaced with nominally divalent cation-free buffer containing inhibitors or vehicle for $10 \mathrm{~min}$ at $37^{\circ} \mathrm{C}$. BzATP or its vehicle (control) was then added. After a further $5 \mathrm{~min}$, buffer was collected and $\mathrm{PGE}_{2}$ levels were measured using $\mathrm{PGE}_{2}$ Express Enzyme Immunoassay kit (Cayman Chemical).

\section{Statistical analyses}

Data are shown as means \pm SEM. Differences between two groups were assessed using $t$ tests. Differences among three or more groups were evaluated by one-way analysis of variance followed by a Tukey multiple comparisons test, or two-way analysis of variance followed by a Bonferroni multiple comparisons test. Differences were accepted as statistically significant at $P<0.05$.

\section{Online supplemental material}

Fig. S1 shows that osteoblasts from both calvariae and long bones express P2rx7 transcripts and that P2X7 receptors on long bone cells are functional. Fig. S2 shows that BzATP does not affect phosphatidylethanolamine levels in rat calvarial cell cultures. Fig. S3 shows that VPC-32183 and NS398 do not affect cell numbers in rat calvarial cell cultures during differentiation. Table $\mathrm{S} 1$ is a list of the custom-designed primer and probe sequences used for real-time RT-PCR analyses. Online supplemental material is available at http://www.jcb.org/cgi/content/full/jcb.200708037/DC1.

We thank Drs. Arthur Sampaio, Lee-Anne Richter, and Anita Woods for help with design of primers and probes for real-time RT-PCR, Drs. David Holdsworth and Joseph Umoh for assistance with microcomputed tomography, and Dr. Frank Beier and Matthew Grol for constructive comments on the manuscript.

This study was funded by the Canadian Institutes of Health Research. J. Rogers was supported by the Canadian Institutes of Health Research Network for Oral Research Training and Health.

Submitted: 6 August 2007

Accepted: 30 April 2008

\section{References}

Adinolfi, E., M.G. Callegari, D. Ferrari, C. Bolognesi, M. Minelli, M.R. Wieckowski, P. Pinton, R. Rizzuto, and F. Di Virgilio. 2005. Basal activation of the $\mathrm{P}_{2} \mathrm{X}_{7}$ ATP receptor elevates mitochondrial calcium and potential, increases cellular ATP levels, and promotes serum-independent growth. Mol. Biol. Cell. 16:3260-3272.

Akiyama, H., J.E. Kim, K. Nakashima, G. Balmes, N. Iwai, J.M. Deng, Z. Zhang, J.F. Martin, R.R. Behringer, T. Nakamura, and B. de Crombrugghe. 2005. Osteo-chondroprogenitor cells are derived from Sox 9 expressing precursors. Proc. Natl. Acad. Sci. USA. 102:14665-14670.

Ali, A.A., R.S. Weinstein, S.A. Stewart, A.M. Parfitt, S.C. Manolagas, and R.L. Jilka. 2005. Rosiglitazone causes bone loss in mice by suppressing osteoblast differentiation and bone formation. Endocrinology. 146:1226-1235.

Anliker, B., and J. Chun. 2004. Lysophospholipid G protein-coupled receptors. J. Biol. Chem. 279:20555-20558.

Baricordi, O.R., L. Melchiorri, E. Adinolfi, S. Falzoni, P. Chiozzi, G. Buell, and F. Di Virgilio. 1999. Increased proliferation rate of lymphoid cells transfected with the P2X 7 ATP receptor. J. Biol. Chem. 274:33206-33208.

Bellows, C.G., and J.E. Aubin. 1989. Determination of numbers of osteoprogenitors present in isolated fetal rat calvaria cells in vitro. Dev. Biol. 133:8-13.

Bligh, E.G., and W.J. Dyer. 1959. A rapid method of total lipid extraction and purification. Can. J. Biochem. Physiol. 37:911-917.

Buckley, K.A., S.L. Golding, J.M. Rice, J.P. Dillon, and J.A. Gallagher. 2003. Release and interconversion of $\mathrm{P} 2$ receptor agonists by human osteoblastlike cells. FASEB J. 17:1401-1410.

Burnstock, G. 2007. Physiology and pathophysiology of purinergic neurotransmission. Physiol. Rev. 87:659-797.

Collo, G., S. Neidhart, E. Kawashima, M. Kosco-Vilbois, R.A. North, and G. Buell. 1997. Tissue distribution of the $\mathrm{P} 2 \mathrm{X}_{7}$ receptor. Neuropharmacology. 36:1277-1283.

Dixon, S.J., and S.M. Sims. 2000. P2 purinergic receptors on osteoblasts and osteoclasts: potential targets for drug development. Drug Dev. Res. 49:187-200

Dixon, S.J., R. Yu, N. Panupinthu, and J.X. Wilson. 2004. Activation of P2 nucleotide receptors stimulates acid efflux from astrocytes. Glia. 47:367-376.

Ducy, P., R. Zhang, V. Geoffroy, A.L. Ridall, and G. Karsenty. 1997. Osf2/Cbfa1: a transcriptional activator of osteoblast differentiation. Cell. 89:747-754.

Enomoto, H., M. Enomoto-Iwamoto, M. Iwamoto, S. Nomura, M. Himeno, Y. Kitamura, T. Kishimoto, and T. Komori. 2000. Cbfa1 is a positive regulatory factor in chondrocyte maturation. J. Biol. Chem. 275:8695-8702.

Flanagan, A.M., and T.J. Chambers. 1992. Stimulation of bone nodule formation in vitro by prostaglandins $\mathrm{E}_{1}$ and $\mathrm{E}_{2}$. Endocrinology. 130:443-448.

Frohman, M.A., T.C. Sung, and A.J. Morris. 1999. Mammalian phospholipase D structure and regulation. Biochim. Biophys. Acta. 1439:175-186.

Frost, H.M. 2001. From Wolff's law to the Utah paradigm: insights about bone physiology and its clinical applications. Anat. Rec. 262:398-419.

Ge, C., G. Xiao, D. Jiang, and R.T. Franceschi. 2007. Critical role of the extracellular signal-regulated kinase-MAPK pathway in osteoblast differentiation and skeletal development. J. Cell Biol. 176:709-718.

Genetos, D.C., D.J. Geist, D. Liu, H.J. Donahue, and R.L. Duncan. 2005. Fluid shear-induced ATP secretion mediates prostaglandin release in MC3T3E1 osteoblasts. J. Bone Miner. Res. 20:41-49.

Grey, A., T. Banovic, D. Naot, B. Hill, K. Callon, I. Reid, and J. Cornish. 2001. Lysophosphatidic acid is an osteoblast mitogen whose proliferative actions involve $\mathrm{G}_{\mathrm{i}}$ proteins and protein kinase C, but not P42/44 mitogenactivated protein kinases. Endocrinology. 142:1098-1106.

Heasley, B.H., R. Jarosz, K.R. Lynch, and T.L. Macdonald. 2004. Initial structure-activity relationships of lysophosphatidic acid receptor antagonists: discovery of a high-affinity $\mathrm{LPA}_{1} / \mathrm{LPA}_{3}$ receptor antagonist. Bioorg. Med. Chem. Lett. 14:2735-2740.

Henderson, J.H., L.Y. Chang, H.M. Song, M.T. Longaker, and D.R. Carter. 2005 Age-dependent properties and quasi-static strain in the rat sagittal suture. J. Biomech. 38:2294-2301.

Hoebertz, A., A. Townsend-Nicholson, R. Glass, G. Burnstock, and T.R. Arnett. 2000. Expression of $\mathrm{P} 2$ receptors in bone and cultured bone cells. Bone. 27:503-510.

Hoebertz, A., S. Mahendran, G. Burnstock, and T.R. Arnett. 2002. ATP and UTP at low concentrations strongly inhibit bone formation by osteoblasts: a novel role for the $\mathrm{P} 2 \mathrm{Y}_{2}$ receptor in bone remodeling. J. Cell. Biochem. 86:413-419.

Hou, B., N. Fukai, and B.R. Olsen. 2007. Mechanical force-induced midpalatal suture remodeling in mice. Bone. 40:1483-1493.

Ke, H.Z., H. Qi, A.F. Weidema, Q. Zhang, N. Panupinthu, D.T. Crawford, W.A. Grasser, V.M. Paralkar, M. Li, L.P. Audoly, et al. 2003. Deletion of the 
$\mathrm{P} 2 \mathrm{X}_{7}$ nucleotide receptor reveals its regulatory roles in bone formation and resorption. Mol. Endocrinol. 17:1356-1367.

Khakh, B.S., and R.A. North. 2006. P2X receptors as cell-surface ATP sensors in health and disease. Nature. 442:527-532.

Komarova, S.V., F.I. Ataullakhanov, and R.K. Globus. 2000. Bioenergetics and mitochondrial transmembrane potential during differentiation of cultured osteoblasts. Am. J. Physiol. Cell Physiol. 279:C1220-C1229.

Lee, C.W., R. Rivera, S. Gardell, A.E. Dubin, and J. Chun. 2006. GPR92 as a new $\mathrm{G}_{12 / 13}$ - and $\mathrm{G}_{\mathrm{q}}$-coupled lysophosphatidic acid receptor that increases cAMP, LPA 5 . J. Biol. Chem. 281:23589-23597.

Lefebvre, V., W. Huang, V.R. Harley, P.N. Goodfellow, and B. de Crombrugghe 1997. SOX9 is a potent activator of the chondrocyte-specific enhancer of the pro $\alpha 1$ (II) collagen gene. Mol. Cell. Biol. 17:2336-2346.

Li, J., D. Liu, H.Z. Ke, R.L. Duncan, and C.H. Turner. 2005. The P2X $\mathrm{X}_{7}$ nucleotide receptor mediates skeletal mechanotransduction. J. Biol. Chem. 280:42952-42959.

Maniatopoulos, C., J. Sodek, and A.H. Melcher. 1988. Bone formation in vitro by stromal cells obtained from bone marrow of young adult rats. Cell Tissue Res. 254:317-330.

Masiello, L.M., J.S. Fotos, D.S. Galileo, and N.J. Karin. 2006. Lysophosphatidic acid induces chemotaxis in MC3T3-E1 osteoblastic cells. Bone. 39:72-82.

Mills, G.B., and W.H. Moolenaar. 2003. The emerging role of lysophosphatidic acid in cancer. Nat. Rev. Cancer. 3:582-591.

Morriss-Kay, G.M., and A.O. Wilkie. 2005. Growth of the normal skull vault and its alteration in craniosynostosis: insights from human genetics and experimental studies. J. Anat. 207:637-653.

Naemsch, L.N., S.J. Dixon, and S.M. Sims. 2001. Activity-dependent develop ment of $\mathrm{P} 2 \mathrm{X}_{7}$ current and $\mathrm{Ca}^{2+}$ entry in rabbit osteoclasts. J. Biol. Chem. 276:39107-39114.

Nakamura, E., Y. Uezono, K. Narusawa, I. Shibuya, Y. Oishi, M. Tanaka, N. Yanagihara, T. Nakamura, and F. Izumi. 2000. ATP activates DNA synthesis by acting on P2X receptors in human osteoblast-like MG-63 cells. Am. J. Physiol. Cell Physiol. 279:C510-C519.

Nakashima, K., X. Zhou, G. Kunkel, Z. Zhang, J.M. Deng, R.R. Behringer, and B. de Crombrugghe. 2002. The novel zinc finger-containing transcription factor Osterix is required for osteoblast differentiation and bone formation. Cell. 108:17-29.

Nishio, Y., Y. Dong, M. Paris, R.J. O’Keefe, E.M. Schwarz, and H. Drissi. 2006. Runx2-mediated regulation of the zinc finger Osterix/Sp7 gene. Gene. 372:62-70.

North, R.A. 2002. Molecular physiology of P2X receptors. Physiol. Rev. 82:1013-1067.

Orriss, I.R., J.C. Utting, A. Brandao-Burch, K. Colston, B.R. Grubb, G. Burnstock, and T.R. Arnett. 2007. Extracellular nucleotides block bone mineralization in vitro: evidence for dual inhibitory mechanisms involving both $\mathrm{P}_{2} \mathrm{Y}_{2}$ receptors and pyrophosphate. Endocrinology. 148:4208-4216.

Panupinthu, N., L. Zhao, F. Possmayer, H.Z. Ke, S.M. Sims, and S.J. Dixon. 2007. P2X7 nucleotide receptors mediate blebbing in osteoblasts through a pathway involving lysophosphatidic acid. J. Biol. Chem. 282:3403-3412.

Pelegrin, P., and A. Surprenant. 2006. Pannexin-1 mediates large pore formation and interleukin- $1 \beta$ release by the $\mathrm{ATP}$-gated $\mathrm{P} 2 \mathrm{X}_{7}$ receptor. $E M B O J$ 25:5071-5082.

Pines, A., M. Romanello, L. Cesaratto, G. Damante, L. Moro, P. D'Andrea, and G. Tell. 2003. Extracellular ATP stimulates the early growth response protein 1 (Egr-1) via a protein kinase C-dependent pathway in the human osteoblastic HOBIT cell line. Biochem. J. 373:815-824.

Riddle, R.C., A.F. Taylor, J.R. Rogers, and H.J. Donahue. 2007. ATP release mediates fluid flow-induced proliferation of human bone marrow stromal cells. J. Bone Miner. Res. 22:589-600.

Robling, A.G., A.B. Castillo, and C.H. Turner. 2006. Biomechanical and molecular regulation of bone remodeling. Annu. Rev. Biomed. Eng. 8:455-498.

Romanello, M., B. Pani, M. Bicego, and P. D'Andrea. 2001. Mechanically induced ATP release from human osteoblastic cells. Biochem. Biophys. Res. Commun. 289:1275-1281

Shimegi, S. 1996. ATP and adenosine act as a mitogen for osteoblast-like cells (MC3T3-E1). Calcif. Tissue Int. 58:109-113.

Solle, M., J. Labasi, D.G. Perregaux, E. Stam, N. Petrushova, B.H. Koller, R.J. Griffiths, and C.A. Gabel. 2001. Altered cytokine production in mice lacking $\mathrm{P}_{2} \mathrm{X}_{7}$ receptors. J. Biol. Chem. 276:125-132.

Turner, J.T., G.A. Weisman, and J.M. Camden. 1997. Upregulation of P2Y nucleotide receptors in rat salivary gland cells during short-term culture. Am. J. Physiol. 273:C1100-C1107.

Yoshida, K., H. Oida, T. Kobayashi, T. Maruyama, M. Tanaka, T. Katayama, K. Yamaguchi, E. Segi, T. Tsuboyama, M. Matsushita, et al. 2002. Stimulation of bone formation and prevention of bone loss by prostaglandin E EP4 receptor activation. Proc. Natl. Acad. Sci. USA. 99:4580-4585.

Zhang, X., E.M. Schwarz, D.A. Young, J.E. Puzas, R.N. Rosier, and R.J. O'Keefe. 2002. Cyclooxygenase-2 regulates mesenchymal cell differentiation into the osteoblast lineage and is critically involved in bone repair. J. Clin. Invest. 109:1405-1415. 